\title{
A Comprehensive Numerical Study on Building-Excavation Interaction
}

\author{
Arman Maddah ${ }^{\mathrm{a}}$, Abbas Soroush ${ }^{\mathrm{a}}$ \\ ${ }^{a}$ Department of Civil and Environmental Engineering, Amirkabir University of Technology, Tehran 1591634311, Iran.
}

Received 02 August 2019; Accepted 27 December 2019

\begin{abstract}
This paper presents results of a plane strain comprehensive numerical study on the interaction between a 31-meter-deep excavation and an adjacent 12-story building; the study emphasizes on parametric analyses with respect to the building characteristics, such as the building width in plan (B), i.e., the side perpendicular to the excavation wall, the embedment depth of the building foundation (D), as well as the building distance to the excavation edge (e). Through the parametric analyses and assuming different values for B, D, and e, settlements and rotations of the building and horizontal displacements of the excavation edge were computed and evaluated using the finite element method adopted in PLAXIS 3D software. Prior to the parametric study, the numerical modeling was verified by modeling a recorded case study, which is an anchored deep excavation adjacent to a 12-story building. The results of the parametric analyses suggest that for the given soil and excavation, (1) the position of the developing potential failure surface, PFS, in the soil behind the excavation is almost independent from the building location and (2) the position of the building with respect to the outcrop of the PFS in the excavation crest, i.e., if the building locates fully on the potential failure wedge or PFS intersect the building base, is the main factor affecting the induced displacements and rotations of the building.
\end{abstract}

Keywords: Deep Excavation; Adjacent Building; Failure Wedge; Numerical Analysis; Parametric Study.

\section{Introduction}

Rapid urbanization has led to growing number of activities, including construction of underground spaces that require cutting of deep excavations proximate to existing buildings. Excavations inevitably induce significant changes in stress/strain states of the surrounding soil, which in turn may cause different levels of displacement and damage in nearby structures [1]. These effects are related to a host of parameters, namely, soil properties, specifications of excavation support system, building properties and location with respect to the excavation, and excavation sequences and geometry [2-7]. In design and construction of deep excavations, it is prudent to avoid excessive lateral displacements and ground surface settlements, by carefully considering the effects of the above-mentioned factors, otherwise uncertainties would often force engineers towards inefficient constructions with high costs [8].

Previous studies have demonstrated that buildings weight, stiffness and position relative to excavations are the main building-related factors influencing excavation-induced deformations of the nearby buildings [3, 9-10]. The stiffness of an adjacent building affects excavation-induced settlements. The bending stiffness and shear stiffness of a building mostly depend on stiffness of frames and in-frame walls, respectively. There are two main methods to include effects of adjacent buildings in numerical modeling of excavations: (1) using an equivalent beam and (2) modeling the building as a frame. In the former, estimation of the stiffness would be appropriate for a building with wall behavior dominancy.

* Corresponding author: soroush@aut.ac.ir

http://dx.doi.org/10.28991/cej-2020-03091474

(C) 2019 by the authors. Licensee C.E.J, Tehran, Iran. This article is an open access article distributed under the terms and conditions of the Creative Commons Attribution (CC-BY) license (http://creativecommons.org/licenses/by/4.0/). 
Despite its widespread use, alternating a simple beam instead of a framed building to represent its real behavior is under discussion [11-13]. Using equivalent surface beam in numerical studies about building-tunneling interaction overestimates stiffness of the building and, therefore, underestimates the induced settlements [14, 15].

Having used the equivalent beam method, Goh and Mair [10] presented building modification factors applicable for determination of adjacent excavation effects on the building deflections and strains. They employed 2D numerical models of weightless framed buildings, with both mat and spread footings, on the crest of a strutted excavation in a soft clay. They also used an equivalent simple beam to represent bending stiffness of the building frame, while neither weight of the building nor the position of the building in relation to the excavation's Potential Failure Surface (PFS) were taken into account [10].

Son and Cording [16] modeled the building and showed that openings (i.e., doors and windows of masonry buildings) reduce significantly the building's shear stiffness (compared to the bending stiffness). They suggested that $30 \%$ increase in walls openings ratio results in 45-61\% reduction in shear stiffness of the equivalent wall [16].

Other studies have indicated that factors such as building structural system, cracking in frame or load-bearing walls and soil conditions affect the response of framed structures to settlements induced by adjacent excavations [17-19].

Thus far, the two main approaches implemented in estimating excavation-induced vertical and horizontal displacements can be classified as empirical (or semi-empirical) methods and numerical modeling. The complex soilstructure interaction can be taken into account only using numerical methods along with an appropriate constitutive law for the soil behavior. Nevertheless, it should be noted that neither of the two methods could be implemented alone if deformations occur due to improper soil excavation or local water leakage into the excavation [20]. However, it is expected that including actual conditions encountered during excavation in numerical models can yield reasonable results.

Application of free-field settlements of excavations to their adjacent buildings has been commonly adopted as a shortcut method for estimating levels of damages to the buildings; of course, this approach ignores effects of the building on the settlement and thus is not adequate for all circumstances [5]. Son and Cording [9] numerically investigated responses of buildings with different structural types, founded on soils with different properties, subjected to progressive free field ground settlements obtained from typical field observations. They indicated that the structural response to excavation-induced ground settlements is highly dependent on the structural type and soil conditions.

Moreover, in order to account for building-excavation interactions in conditions in which the side corners of the excavation are not far enough from the building and also for special geometries of narrow, deep excavations, only 3D models should be used [21-23]. Meanwhile, attempts have been made to correlate plane-strain analyses results to their corresponding 3D analyses [24-25].

Owing to the variety of parameters involved in the interaction behavior of excavations and nearby buildings, no comprehensive study considering the impact of all influencing parameters has so far been conducted. The deformations seem to be better interpreted by considering the building position with respect to the Potential Failure Wedge (PFW) developed in the soil during excavation; this has not been accounted for in the literature. Moreover, stability analyses regarding the building location in relation to the excavation wall have been rarely taken into account. The reason may be attributed to the difficulties involved in investigating simultaneously the excavation stability and induced deformations in a parametric study.

This study attempts to understand how specifications of a framed building in the vicinity of a deep excavation affect the excavation induced deformations. To this end, the PLAXIS 3D-2017 software is incorporated to perform Finite Element analyses. The modeling approach is verified first using the monitoring data from a $31.2 \mathrm{~m}$ deep excavation and then used for numerical modeling of a series of anchored piled excavations. Extensive sensitivity analyses with regard to the parameters related to the building's location (range of which were determined based on the results of the stability analyses) are carried out. The results of the analyses are presented in terms of rotations and settlements of the building and displacements of the excavation crest.

The research methodology of the present study is presented in a flowchart as depicted in Figure 1. 


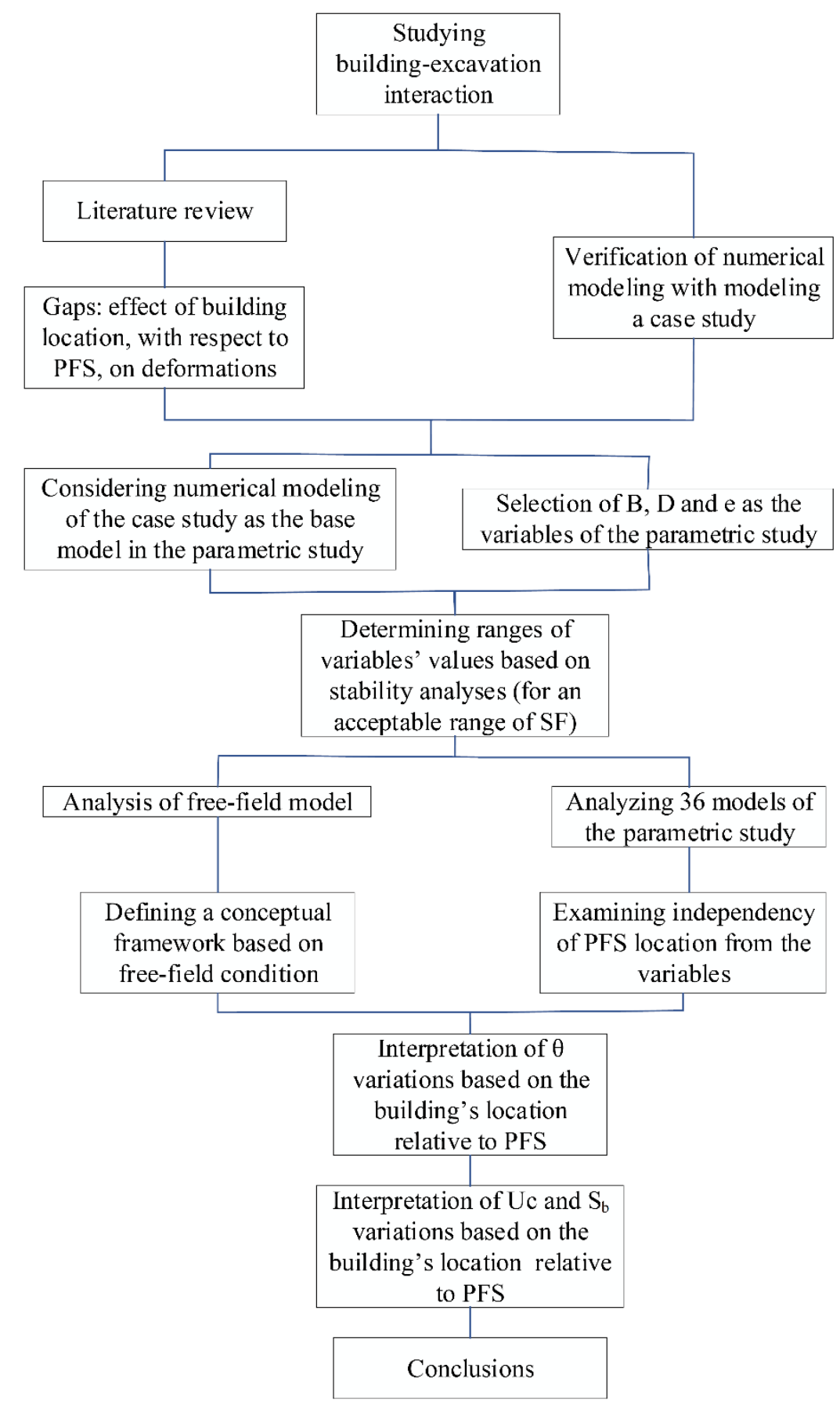

Figure 1. Flowchart of the research methodology (PFS: potential failure surface, main variables: B (building width perpendicular to the excavation wall), e (building distance to the excavation edge) and $D$ (embedment depth of the building foundation), SF: safety factor, $\theta$ : building rotation, $U_{c}$ : excavation edge horizontal deformation, $S_{b}$ : maximum building settlement)

\section{Case Study}

The case under study herein is a part of the west side of a $31.2 \mathrm{~m}$ deep excavation project, adjacent to a 12-storey building in north of Tehran. The retaining system of this part of the excavation is anchored piles together with a layer of reinforced shotcrete. Geotechnical investigations in the site of the project characterized the soil as a relatively compact, granular, cementitious soil. The ground water table was lower than the excavation base level. Figure 2 depicts plan view of the excavation site and two photos from the excavation wall and the building.

\subsection{Support System}

The support system applied to provide stability and control deformations in vicinity of the building utilizes the combination of pile, anchorage, wire mesh and shotcrete. After drilling the pile locations up to the depth of $34.2 \mathrm{~m}$ 
(embedded in concrete with depth of $3 \mathrm{~m}$, below the excavation bottom to provide fixity), steel piles (2IPE360) with 3 $\mathrm{m}$ spacing were installed. In each sequence of soil excavation, one row of post-tensioned anchors together with a layer of reinforced shotcrete were implemented. Thickness of the shotcrete layer was about $10 \mathrm{~cm}$. Two sets of four and six multi strand anchors ( 0.6 inch diameter for each strand) with $150 \mathrm{kN}$ post tension force for each strand were used (Figure $3)$. Therefore, post tension force for each anchor in the upper three rows and in the lower seven rows of anchors were about $600 \mathrm{kN}$ and $900 \mathrm{kN}$, respectively.
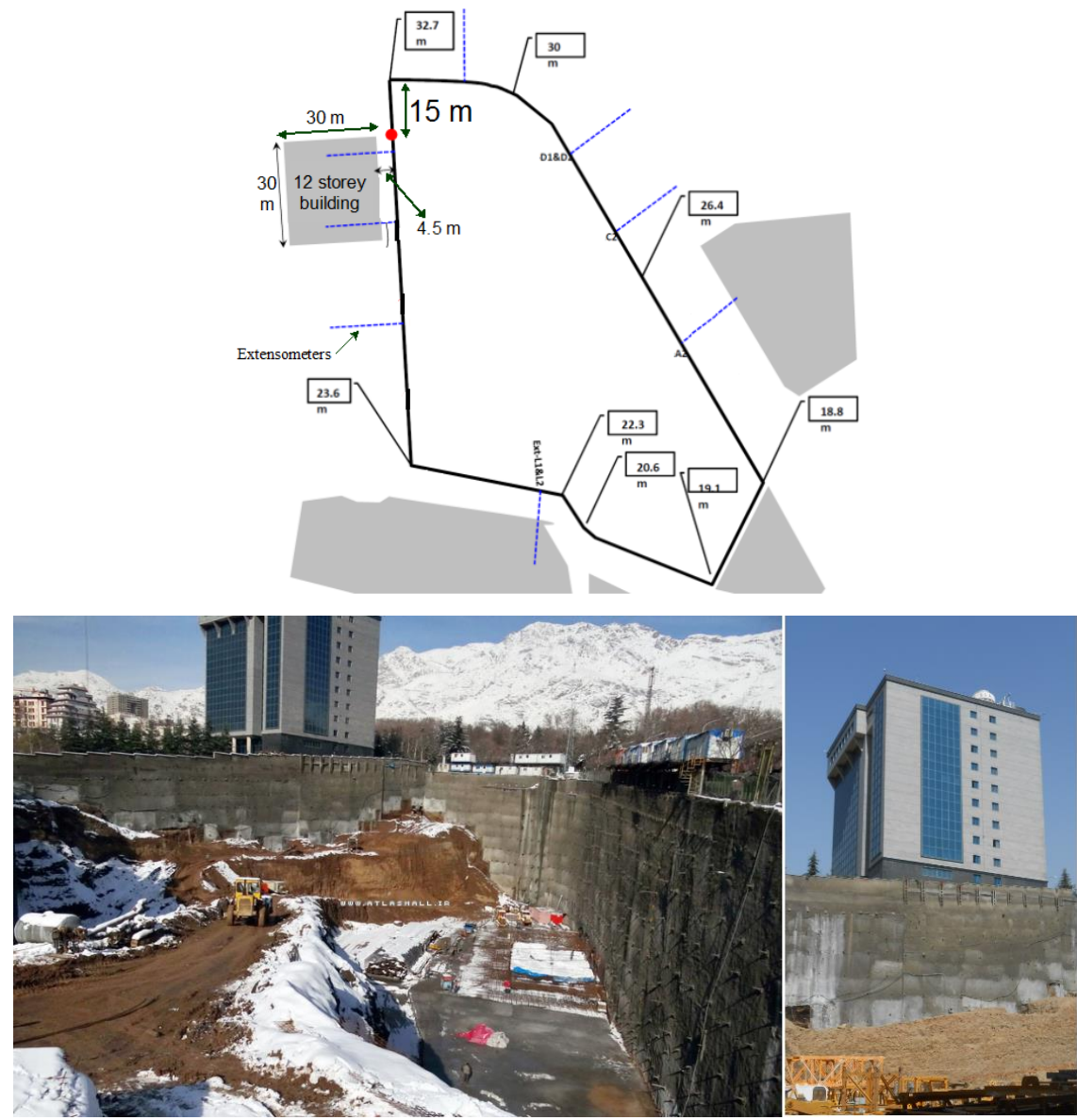

Figure 2. Excavation Plan of the Case Study and View of the building and the excavation wall

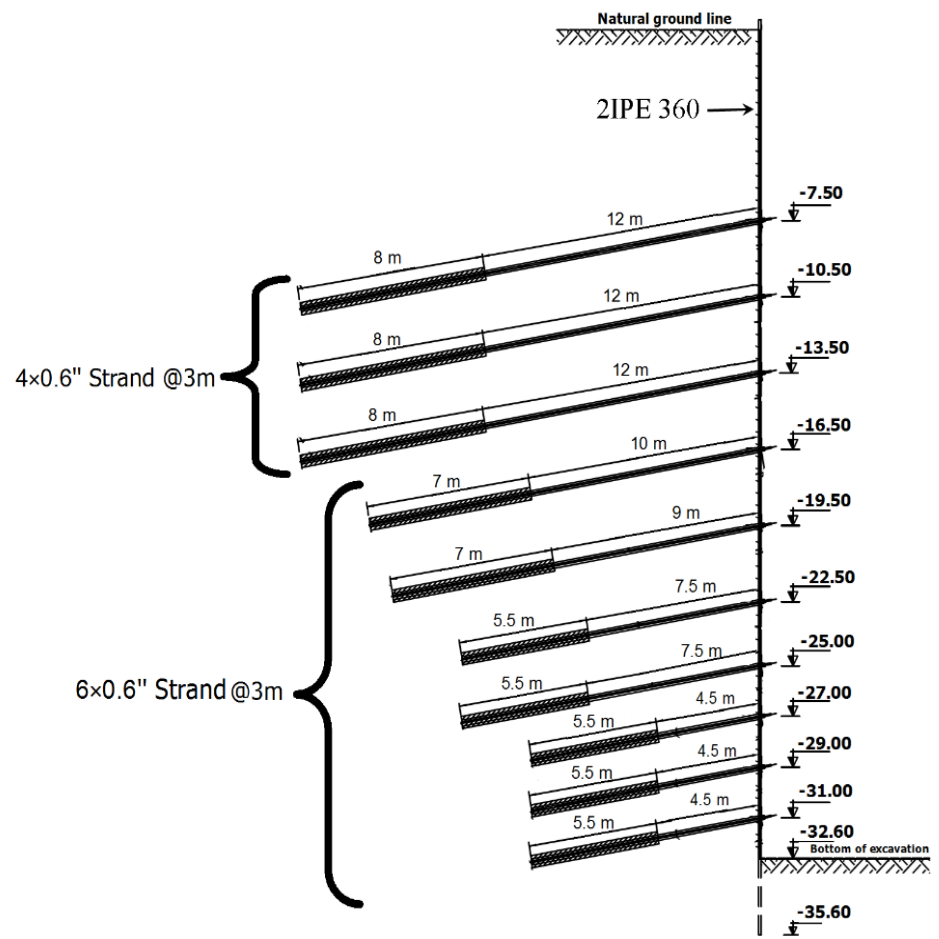

Figure 3. Specifications of the excavation support system 


\subsection{Building Characteristics}

A 12-storey square-shaped (in plan) concrete building, including two basements, with the width of $30 \mathrm{~m}$ and a $1.5 \mathrm{~m}$ thick mat foundation is located in the west side of the excavation (Figure 2). The horizontal distance between the building and the excavation wall (e) is $5 \mathrm{~m}$ and the embedment depth of the foundation is $4.5 \mathrm{~m}$. Regarding the two basements, retaining walls with a thickness of $20 \mathrm{~cm}$ and floors of $20 \mathrm{~cm}$ thick two-way concrete slab have been constructed. Spacing of the columns (bay widths) is almost $6 \mathrm{~m}$ and shear as well as partition walls have occupied around $60 \%$ of the frames. In average, the columns are $70 \mathrm{~cm}$ in dimension while the beams are $30 \mathrm{~cm}$ wide and $50 \mathrm{~cm}$ deep.

\subsection{Instrumentation and Monitoring}

Different instruments such as extensometers, load-cells and tilt-meters were employed to monitor the deflections, anchors forces and building rotations respectively. However, the instruments' data were not trustworthy due to their low quality and improper/incorrect installation. Therefore, the measured displacements of surveying target points (three on the building, B-U-1, B-M-1 and B-D-1 and one on the excavation wall, W-1-2) as shown in Figure 4 were used for verification of the numerical modeling.

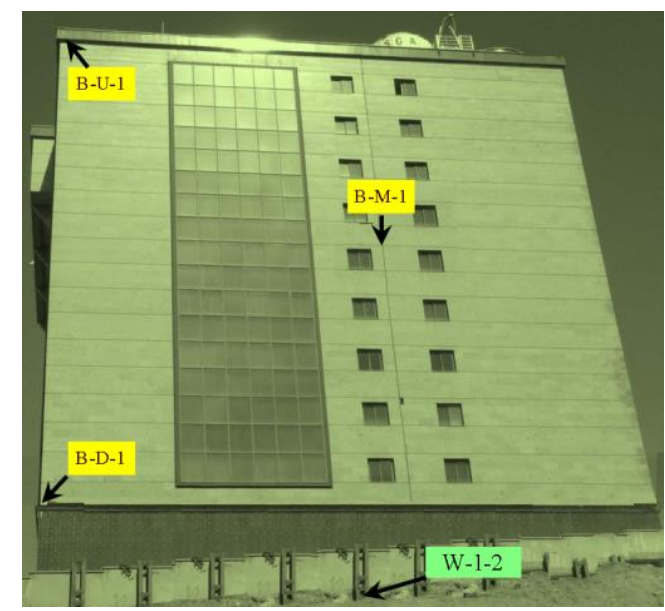

Figure 4. Selected target points on the excavation wall and the adjacent building

\section{Numerical Modeling}

Numerical analyses of the interaction behavior include modeling of both the building and the excavation in four modes of Soil, Structure, Mesh and Staged construction. The numerical modeling and analyses employed the elastoplastic Hardening Soil (HS) constitutive model adopted in PLAXIS 3D [21]. The HS model differentiates between the loading moduli (i.e., $\mathrm{E}_{50}$ or $\mathrm{E}_{\mathrm{i}}$ in Figure $5 \mathrm{a}$ ) and the unloading/reloading $\left(\mathrm{E}_{\mathrm{ur}}\right)$ modulus, and can be confidently used for deep excavation analysis [26]. This model is based on the Mohr-Coulomb strength criterion and two families of yielding surfaces. The yield surfaces are the "yield cap surface", with an associated flow rule, taking into account volumetric plastic strains and the "shearing yield surface" which is used to compute distortional plastic strains. The flow rule is non-associated and the plastic potential function is defined to ensure a hyperbolic response [27]. The stress-strain behavior of the HS Model is depicted in Figure 5 and the Model parameters and their assigned values for the numerical modeling of the case study as well as the fore-coming parametric study are presented in Table 1. By defining a borehole in the Soil mode of the modeling process, the thickness and constitutive model of the soil layer were assigned.

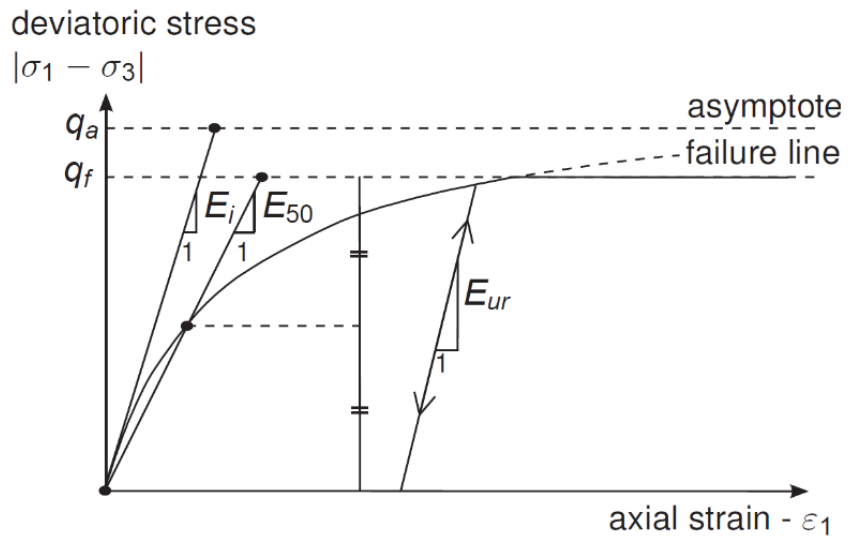

a) Hyperbolic stress-strain relation in primary loading for a standard drained triaxial test

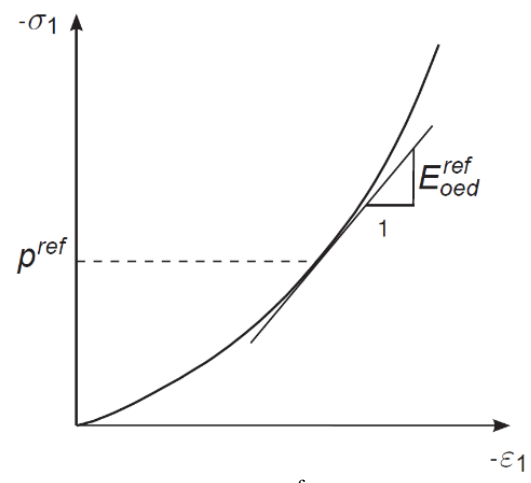

b) Definition of $\mathrm{E}_{\text {oed }}{ }^{\text {ref }}$ in oedometer test results

Figure 5. Characteristics of Hardening Soil model [27] 
Table 1. Soil Properties and HS Model Parameters used in numerical analyses

\begin{tabular}{cccccccccccc}
\hline \multirow{2}{*}{ Property } & $\mathbf{E}_{\mathbf{5 0}}{ }^{\text {ref }}$ & $\mathbf{E}_{\text {oed }}{ }^{\text {ref }}$ & $\mathbf{E}_{\text {ur }}{ }^{\text {ref }}$ & Power, $\mathbf{m}$ & $\mathbf{c}_{\text {ref }}^{\prime}$ & $\boldsymbol{\varphi}$ & $\boldsymbol{\Psi}$ & $\mathbf{v}_{\text {ur }}^{\prime}$ & $\mathbf{P}_{\text {ref }}$ & $\mathbf{K}_{\mathbf{0}}{ }^{\mathbf{n c}}$ & $\gamma$ \\
& $\mathbf{M P a}$ & $\mathbf{M P a}$ & $\mathbf{M P a}$ & - & $\mathbf{k P a}$ & $\mathbf{0}$ & $\mathbf{0}$ & - & $\mathbf{k P a}$ & - & $\mathbf{k N} / \mathbf{m}^{\mathbf{3}}$ \\
\hline Case study & 60 & 60 & 300 & 0.6 & 50 & 39 & 5 & 0.2 & 100 & 0.37 & 20 \\
Parametric study & 60 & 60 & 300 & 0.5 & 25 & 36 & 0 & 0.2 & 100 & 0.41 & 20 \\
\hline
\end{tabular}

* "ref" denotes the reference pressure for triaxial or oedometer test in which the model's parameters should be determined.

The structural elements of the building (i.e., beams, columns, slabs, in-frame walls and foundation) as well as the support system (i.e., piles, anchors and reinforced shotcrete layers) were created in the Structure mode in PLAXIS. The structural model studied here is a $6 \mathrm{~m}$ wide slice from the $30 \times 30 \mathrm{~m}$ square shaped in-plan building. As shown in Figure 2 , the building is about $15 \mathrm{~m}$ away from the excavation corner; therefore, plane strain conditions with an acceptable accuracy applies to the analysis. To ensure a representative frame for the building (regarding the typical $6 \mathrm{~m}$ bay width of the building frame), two anchored piles were incorporated into the model. The unit weight of the structural elements of the building were taken into account by assigning $12 \mathrm{kPa}$ equivalent load (sum of the dead load plus the live load) for each floor of the building.

The shotcrete and piles were modeled with plate elements, while for the bond length of the anchors, embedded beam elements were used. It is worthwhile mentioning that plate elements for modeling the piles were selected to account for the lateral earth pressure on them [27]. Moreover, a block of "volume" element with concrete properties was added to the plate element to model the embedded part of each pile. Furthermore, structural elements such as beam, column, slab, foundation and retaining and in-frame walls were modeled as plate elements.

The PLAXIS 3D program allows for a fully automatic generation of finite element meshes which takes into account the soil layer as well as all structural elements and boundary conditions. After defining the structural elements, mesh generation process in the Mesh mode, by selecting finer mesh sizes around the building zone of the soil body, was conducted. The generated mesh and model's geometry are shown in Figure 6a.

The finite element calculations involve several sequential phases. Each calculation phase corresponds to a particular loading or construction stage. After initial $\mathrm{K}_{0}$ stress analyses in the first phase of the Staged construction mode, the adjacent building and the piles were erected in the second phase of the modeling. Then in the third phase, the first stage of excavation and activation of the supporting system (i.e., anchorage and mesh installation and shotcreting) was modeled according to the practice and excavation geometry of the real project. This phase was repeated for 9 more stages until reaching the final excavation level. Deformations computed at the end of each phase were computed and recorded; in reality however, only deformations pertinent to the excavation stages are of concern.

\subsection{Verification of Numerical Model by the Case Study}

The soil removal in vicinity of the building was carried out in the sequence as depicted in Figure $6 \mathrm{~b}$. The actual excavation sequence was obtained using the available photos/reports. There is a real doubt regarding the efficiency of this excavation sequence as far as controlling of ground deformations [28] is concerned. However, the same excavation sequence was employed in the numerical modeling to follow the real field conditions. Simultaneous with each layer of soil removal, a row of anchors was activated.

Figures 7 shows the comparison of the measured and computed horizontal displacements and settlements of the building and excavation at the target points, during excavation. As seen, the computed results and surveying data are in good harmony with each other in all of excavation stages; this verifies the numerical modeling approach.

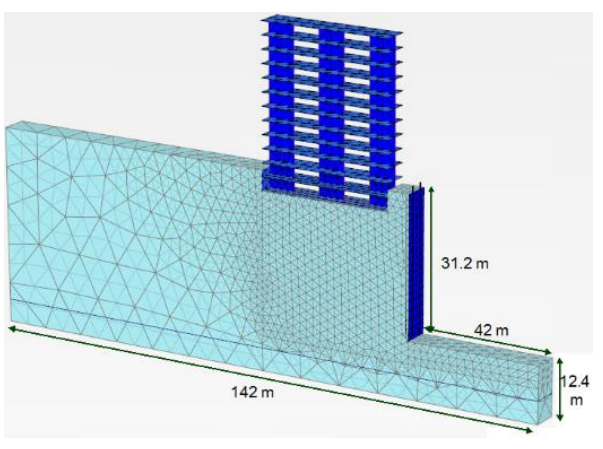

(a) Mesh idealization

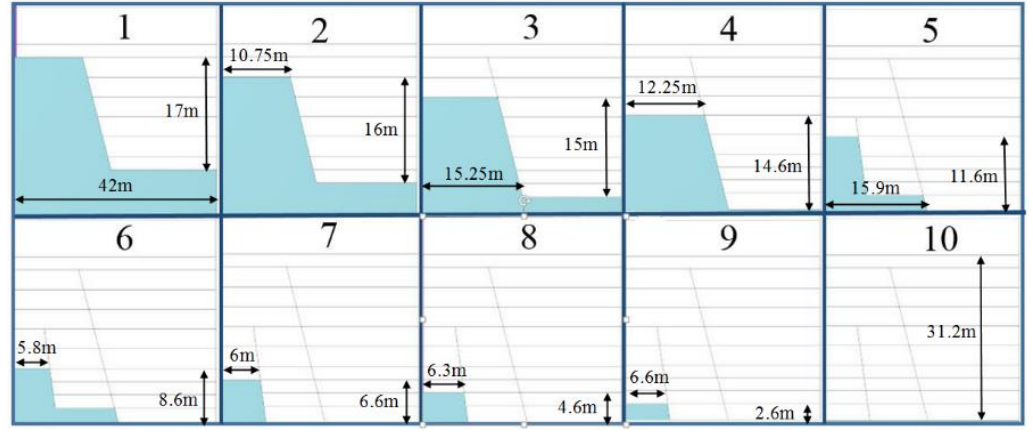

(b) Real excavation stages of the case study

Figure 6. (a) Mesh idealization of the western side (adjacent to the 12-storey building) of the deep excavation case study and (b) Real excavation stages of the case study 

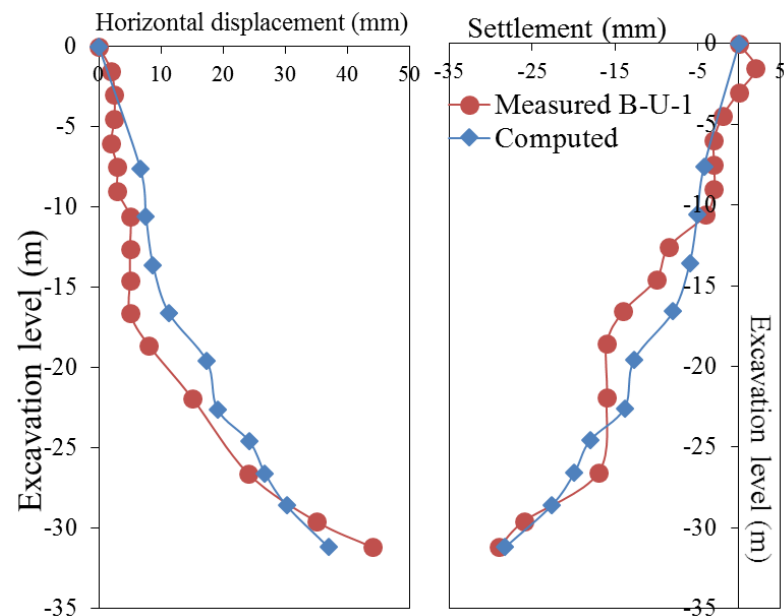

(a) B-U-1 (top of the building)
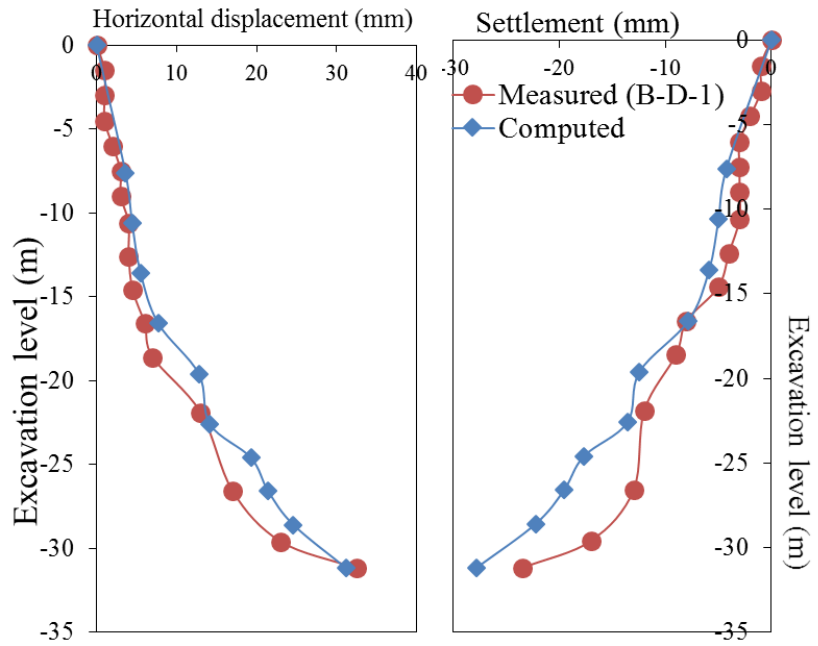

(c) B-D-1 (base level of the building)

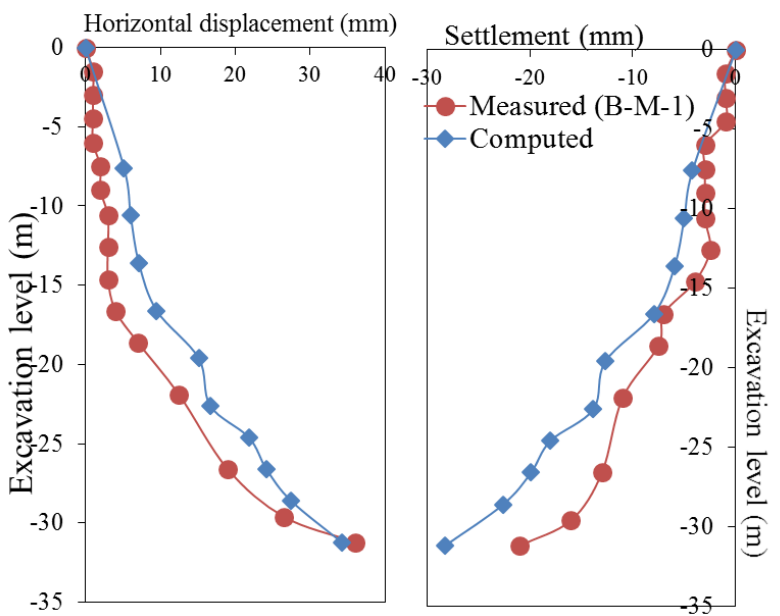

(b) B-M-1 (middle height of the building)

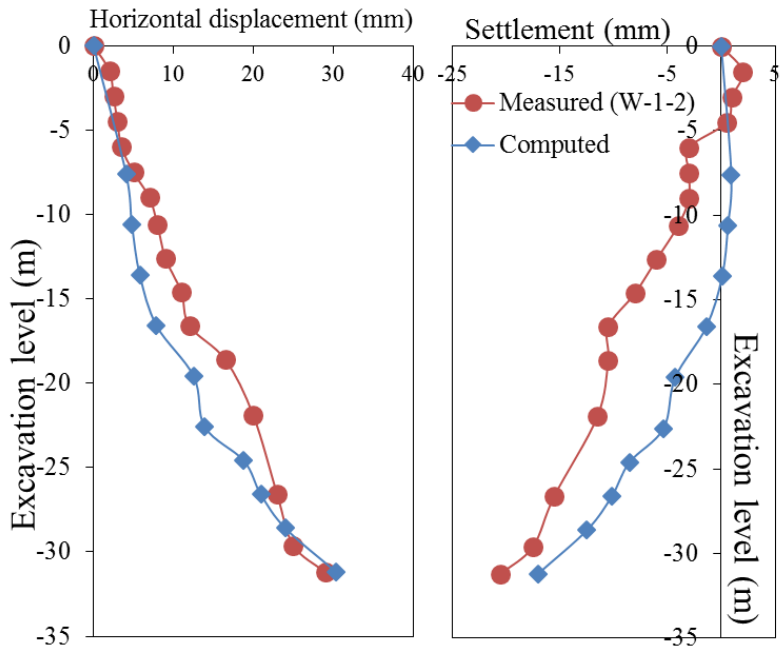

(d) W-1-2 (crest of the excavation)

Figure 7. Comparison of measured and computed deformations for the target points

Further sensitivity analyses showed that the most favorable results are obtained when the bottom boundary condition is about $12.5 \mathrm{~m}$ below the excavation floor. Accordingly, in the cases where the soil layer at the bottom of the excavation are thicker (i.e., more than $12.5 \mathrm{~m}$ in this model), the computed horizontal and vertical displacements differ substantially from the measured ones due to unreal heave of the soil layer beneath the excavation bottom.

\subsection{Parametric Study}

The stiffness and weight of the adjacent building are the two most building-related factors influencing excavationinduced deformations according to the literature. Another important factor affecting the behaviors of both building and excavation is the relative position of the building with respect to the Potential Failure Surface (PFS), which develops within the soil. This relative position depends, of course, on the embedment depth (D), width (B) and distance of the building from the excavation (e), as shown in Figure 8.

Considering all of the above factors and selecting the soil, excavation, and building (i.e., 12-story and $36 \mathrm{~m}$ tall) similar to those of the case study introduced in Section 3, totally 36 building-excavation models were developed. Table 1 presents the parameters of the soil and the $31.2 \mathrm{~m}$ deep excavation wall.

Deformations of the excavation and the building depend on the excavation support design, which in turn is a function of soil characteristics as well as the loading (building location, width and depth). Two approaches may be opted for in the parametric study of the excavation-building interaction. The first approach is to assume an identical Support of Excavation (SOE) for different loadings, and the other one is to consider an identical Factor of Safety (FOS) for the SOEs under different loadings; obviously in the latter approach, the SOE characteristics are case-dependent and depend on the loading conditions. The first approach was adopted in this study. For a realistic comparison of the results, however, the ranges of the parameters of interest were defined in a way that the stability of the SOE is satisfied, in an allowable range of factor of safety, for every loading conditions assumed. To this end, the admissible range of the variables given in Table 2 were assigned based on the stability analyses carried out by Geoslope software, with allowable FOS ranging between 1.2 to 1.6 . 

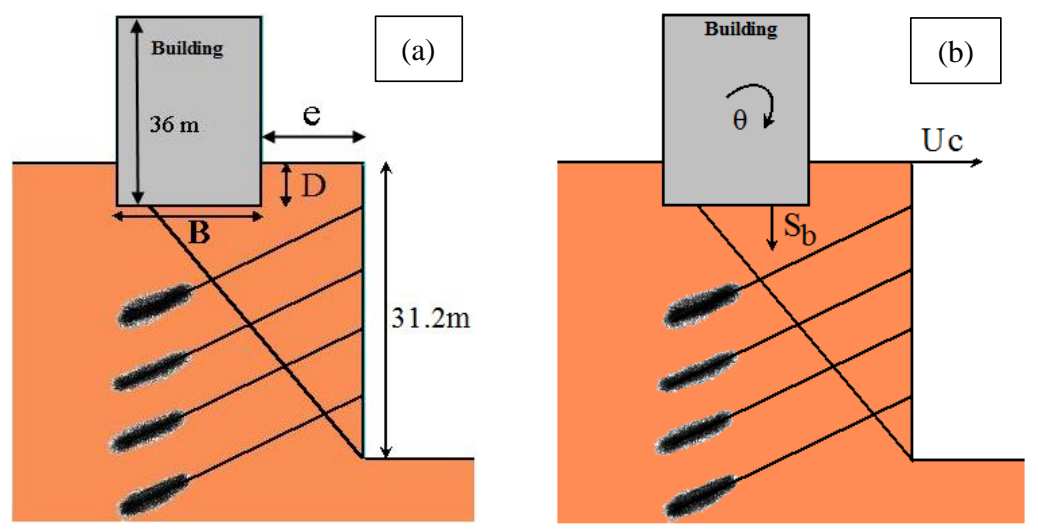

Figure 8. Problem Description; (a) main variables in the parametric study (the building horizontal distance from the excavation (e), foundation depth of the building (D) and the building width (B)), (b) response parameters (horizontal displacement of crest $\left(U_{c}\right)$ and maximum settlement $\left(S_{b}\right)$ and rotation $(\theta)$ of building).

Table 2. Values of the main variables applied in parametric study

\begin{tabular}{cc}
\hline Parameter & Assumed values (m) \\
\hline B & $12,18,30$ \\
E & $0,6,12,18$ \\
D & $2,4.5,6$ \\
\hline
\end{tabular}

Table 3. The cases with the most and the least safety factors in the parametric study

\begin{tabular}{ccccc}
\hline Model & e $(\mathbf{m})$ & $\mathbf{D}(\mathbf{m})$ & $\mathbf{B}(\mathbf{m})$ & F.S. \\
\hline Case study & 6 & 4.5 & 30 & 1.4 \\
Most stable & 18 & 6 & 12 & 1.6 \\
Least stable & 0 & 2 & 30 & 1.2 \\
\hline
\end{tabular}

The results are presented in forms of horizontal displacement of the excavation crest $\left(\mathrm{U}_{\mathrm{c}}\right)$, maximum settlement of the adjacent building $\left(S_{b}\right)$ and rotation of the building $(\theta)$, as shown in Figure 8b; these parameters are interpreted based on the concept of relative position of the building with respect to the PFS. For a better interpretation of the results, a simplified statement has been developed in a conceptual framework related to free field conditions (see Se.4.2).

\section{Results of Parametric Studies}

PFS positions within the soil for different values of the main variables is defined in this section and thus the results of the parametric study are interpreted on the grounds of the building's position in relation to the PFS position along with the contribution of the building stiffness and weight in the failure wedge.

\subsection{Potential Failure Surface Position}

For investigating the dependency of the response parameters to the situation of the building relative to the PFS, it is needed to determine PFS position in the models. The location of PFS can be determined by means of the mobilized shear stress ratio, $\tau_{\text {rel }}$, (Figure $9 a$ ), total principal strain value and direction in the soil (Figure $9 b$ ), and the deformed finite element mesh (Figure 9c); however, the recent approach is not as precise as the two former methods.

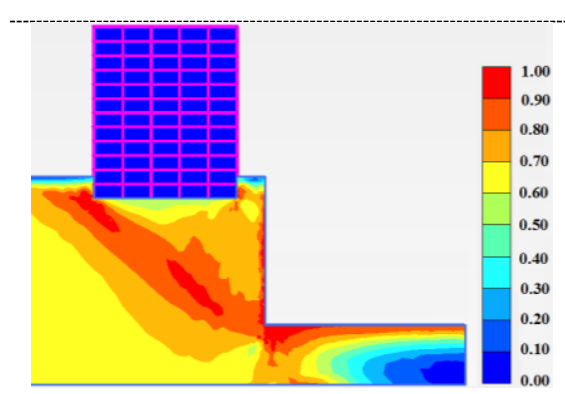

a) Relative shear stress $\left(\tau_{\text {rel }}\right)$

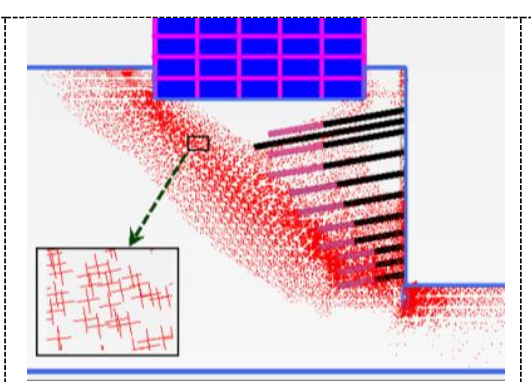

b) Total principal strain values and directions (magnified $\times \mathbf{1 0 0})$

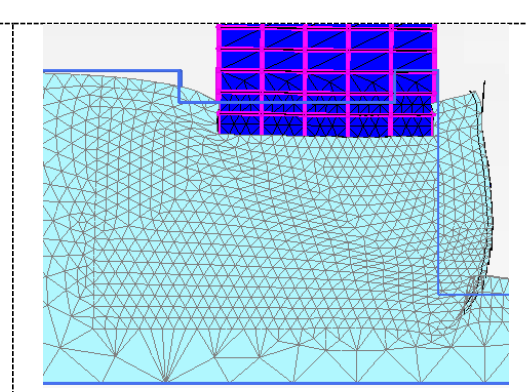

c) Deformed mesh (magnified $\times 100)$

Figure 9. Three methods for assessment of the failure wedge in finite element models

Inspection of relative shear stresses and principal strains directions in Figure 10 (e.g., e=3 m) reveals a clearly distinguishable shear band, delimited in red color. Moving away the building (e.g., e=12 $\mathrm{m}$ in Figure 10) results in fading 
of the red band of the PFS and appearance of local red zones (with high relative shear stress) at immediately below the foundation corners. However, the trace of the red band as an indication of PFS still exists in the lower elevations of the soil near the excavation toe. It is noteworthy that the local effects of strain localization at the corner of the building foundation is ignored and the location of the PFS is mainly determined on the basis of shear band trace passing through the excavation toe.

Figure 10 illustrates changes of PFS position in the soil body for different values of e. As seen, changing the building distance from the excavation wall (e) has negligible effects on the PFS position. It can be realized that changing the building width (B), does neither distinguishably alter the PFS position (Figure 11). In other words, the PFS resists against changes in its position for different values of e and B of the building. Similarly comparing the PFS position for different values of the foundation depth of the building indicated that increase in D values also has no noticeable effect on the PFS position. Thus, it can be concluded that the PFS position is almost independent of the main parameters (i.e., B, D and e) considered in the analyses.

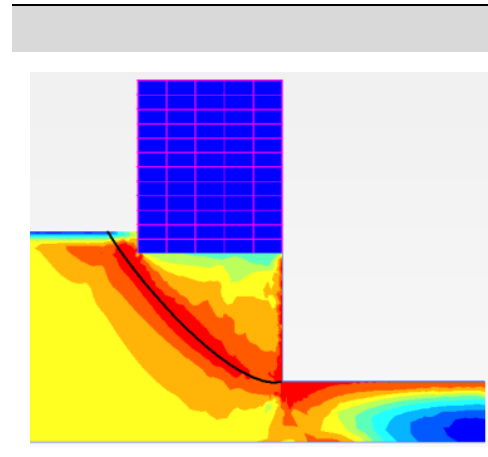

(a)

\section{$\mathrm{e}=0$}

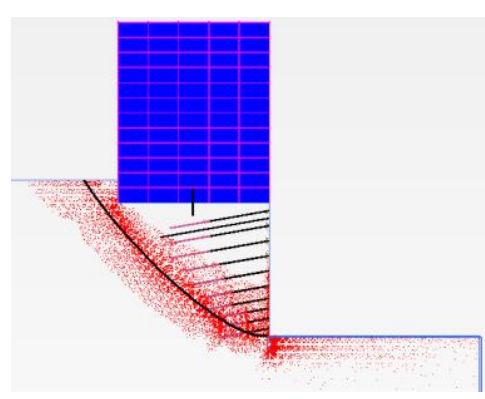

(b)

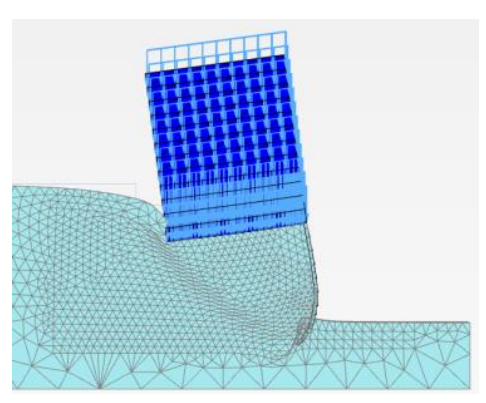

(c)

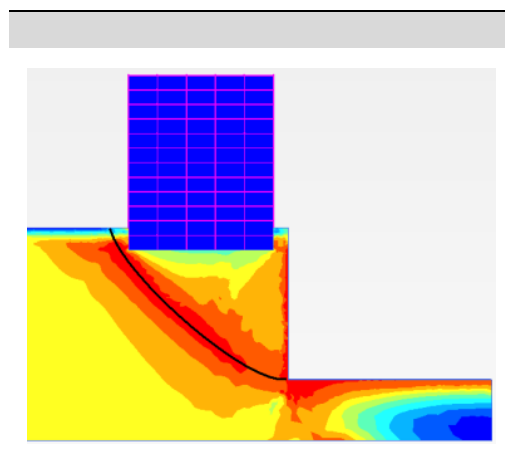

(d)

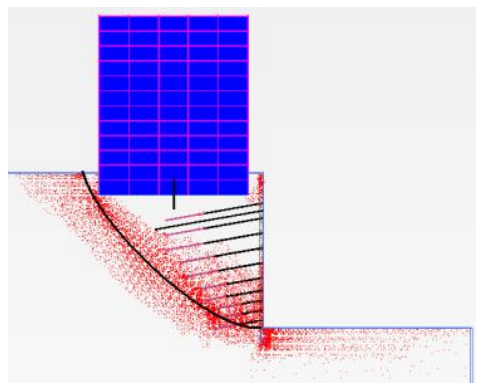

(e)

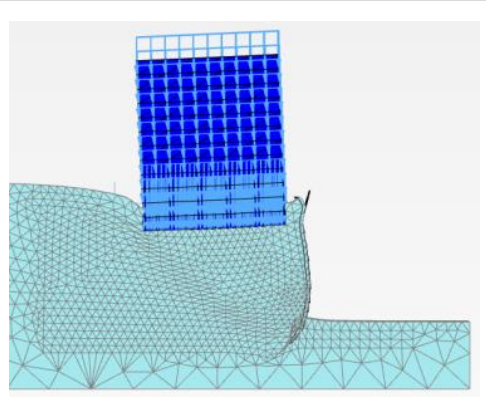

(f)

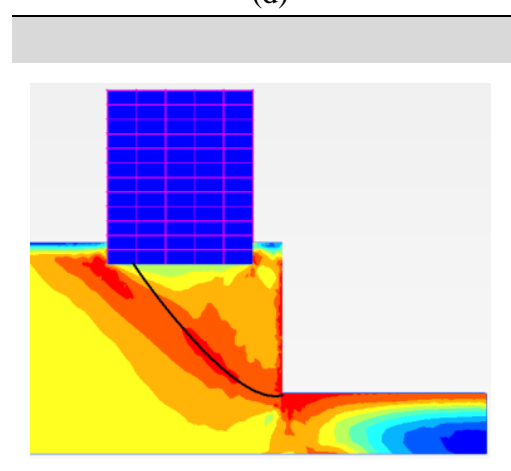

(g)

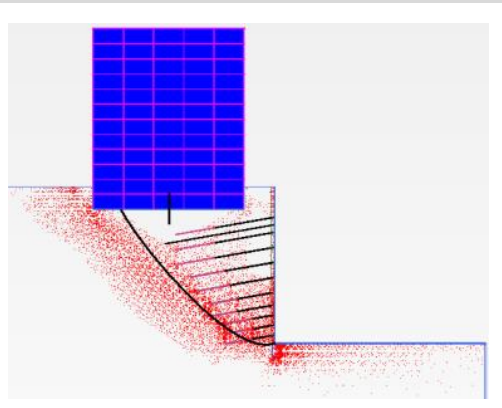

(h)

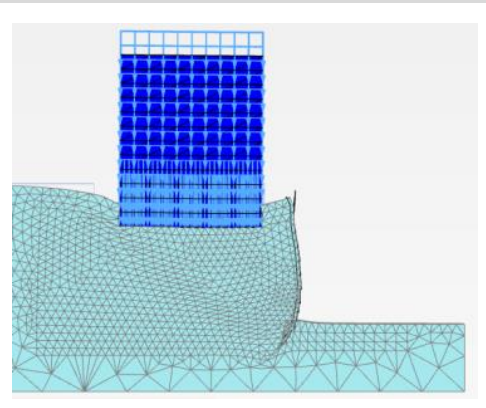

(i)

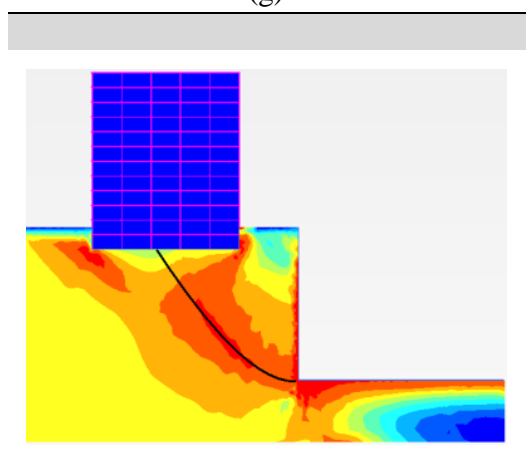

(j)

$\mathrm{e}=12 \mathrm{~m}$

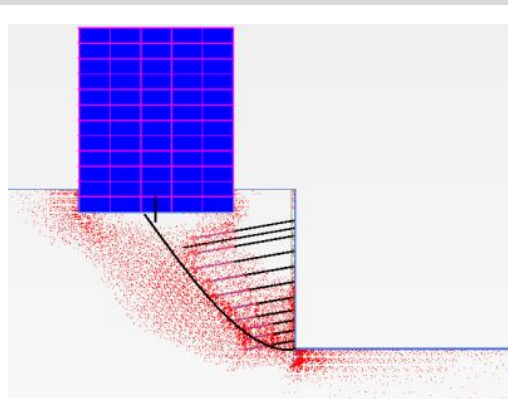

(k)

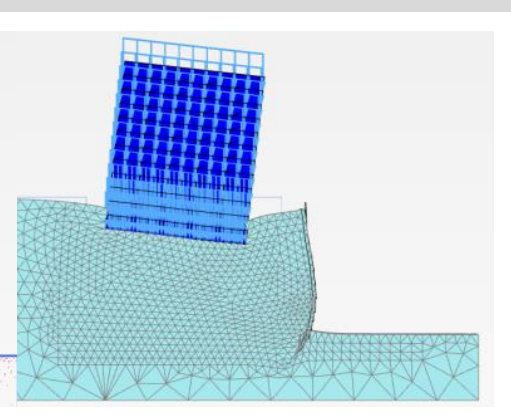

(1) 


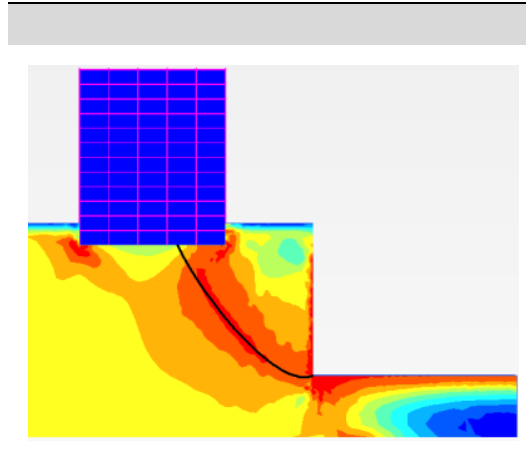

(m) $\mathrm{e}=18 \mathrm{~m}$

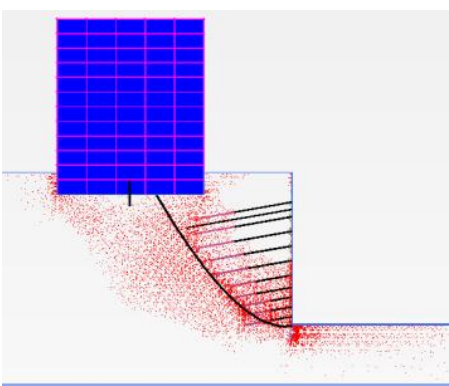

(n)

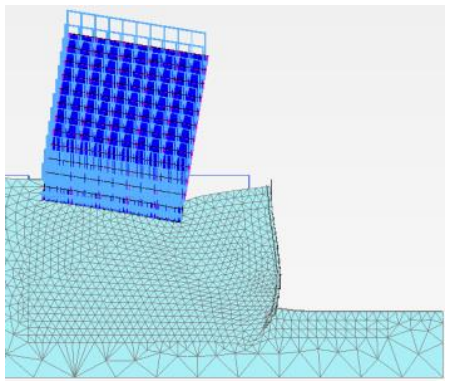

(o)

Relative shear stress $\left(\tau_{\text {rel }}\right)$

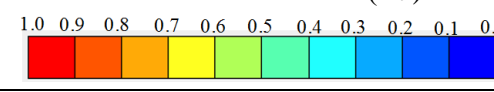

Total principal strain

Deformed mesh

Figure 10. Indication of potential failure surface for different values of e ( $B=30 \mathrm{~m}$ for all cases)

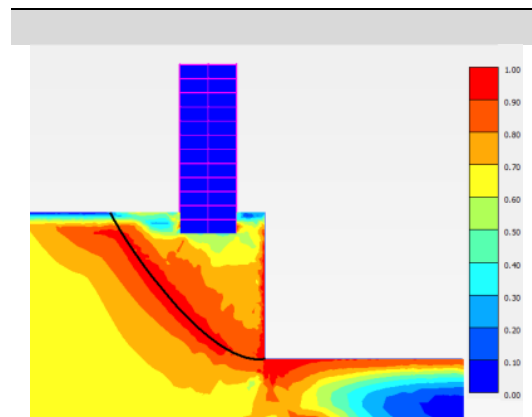

(a)

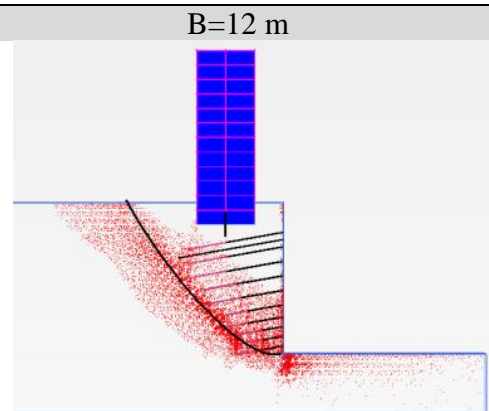

(b)

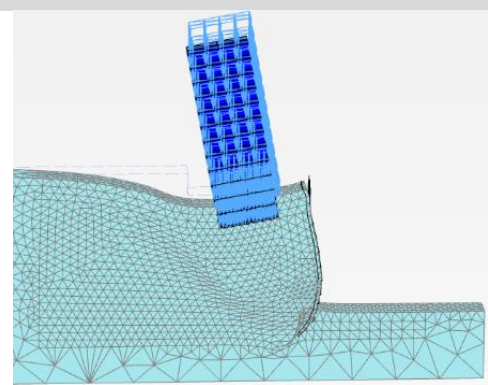

(c)

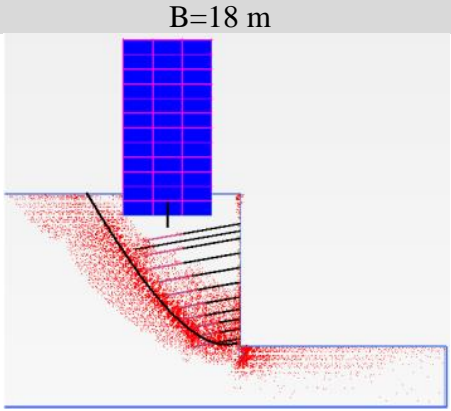

(e)

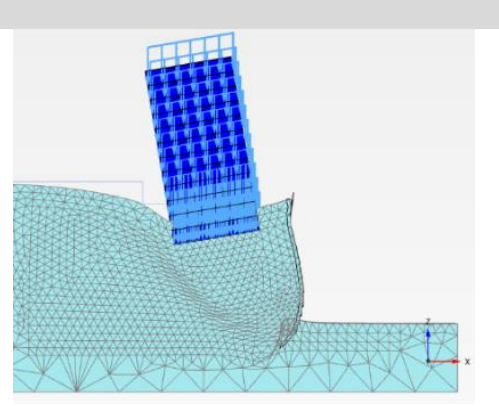

(f)

(d) $B=24 \mathrm{~m}$

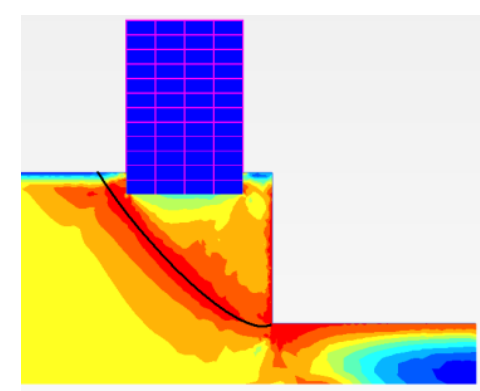

(g)

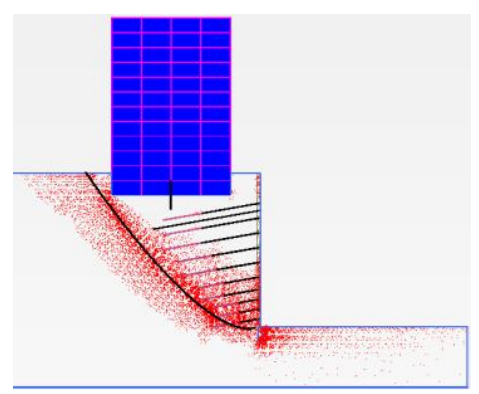

(h)

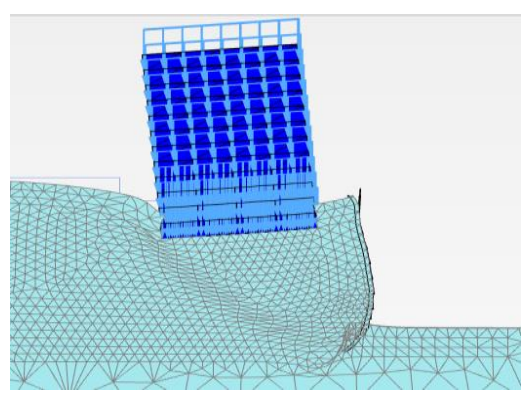

(i)

$\mathrm{B}=30 \mathrm{~m}$ 


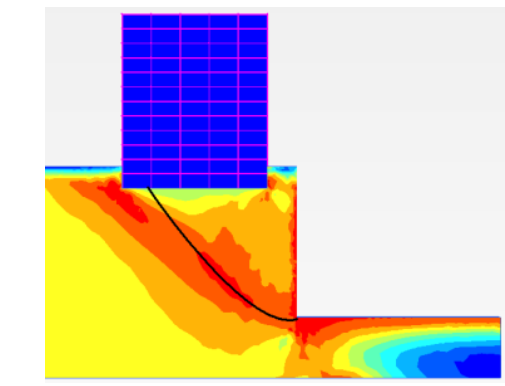

(j)

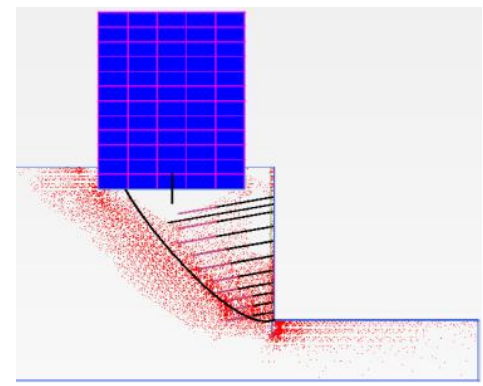

(k)

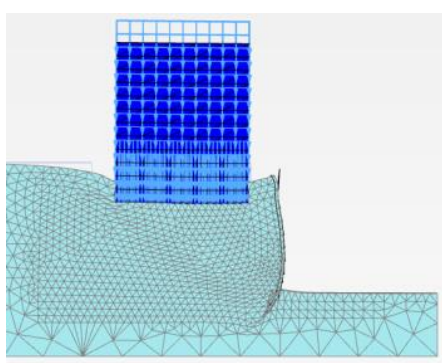

(1)

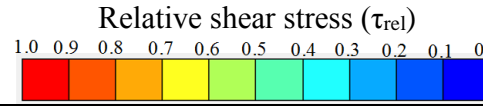

Total principal strain

Deformed mesh

Figure 11. Indication of PFS for different values of $B$ ( $e=4.5 \mathrm{~m}$ for all cases)

\subsection{Building Rotation ( $(\theta)$}

This section investigates variations of building rotation $(\theta)$ because of excavation-induced deformations. Developing a conceptual framework, in the first stage, the impacts of the location of a hypothetical building with respect to the PFS (Figure 12a) on the building rotation are described based on the ground surface settlement profile in the free field model (Figure 12b); $\theta$ is calculated based on differential settlements of the mat foundation. Figure 12c illustrates $\theta$ variations of a hypothetical building with $\mathrm{D}=0$ versus " $\mathrm{e}+\mathrm{B} / 2$ " for different values of $\mathrm{B}$ and $\mathrm{e}$. Here, "e+B/2" is the distance of the building foundation midpoint from the excavation edge. Comparison of the building rotation for different values of $\mathrm{e}$ and $\mathrm{B}$ in Figure 12c implies that the rotation direction of the hypothetical building alters almost at $\mathrm{e}+\mathrm{B} / 2=20 \mathrm{~m}$, corresponding to the point of maximum ground settlement in free field conditions (Figure 12b).

The location of the maximum settlement may correlate geometrically to the PFS location. In other words, for $\mathrm{e}+\mathrm{B} / 2<20 \mathrm{~m}$ the building mainly locates inside the PFW (where rotations are counter clockwise according to the ground surface settlement profile). As e+B/2 exceeds $20 \mathrm{~m}$ the building tends to move outside the PFW, with smaller settlements and yielding clockwise rotations. Thus, the rotation of the hypothetical building may correlate to its relative location with respect to PFS.

This trend is also obvious for real buildings as were indicated in Figures 10 and 11, in which vertical black lines under the buildings (in the figures related to total principal strain directions) show the location of building midpoint with respect to PFS. It is of interest to compare the rotation direction of the corresponding building in the deformed mesh figures with the position of the above vertical black line in Figures 10 and 11. It can be seen that in the presence of the real building, zero rotation also occurs when $\mathrm{e}+\mathrm{B} / 2 \approx 20 \mathrm{~m}$. This compatibility suggests that the building rotation is highly dependent to its relative position with respect to the PFS.
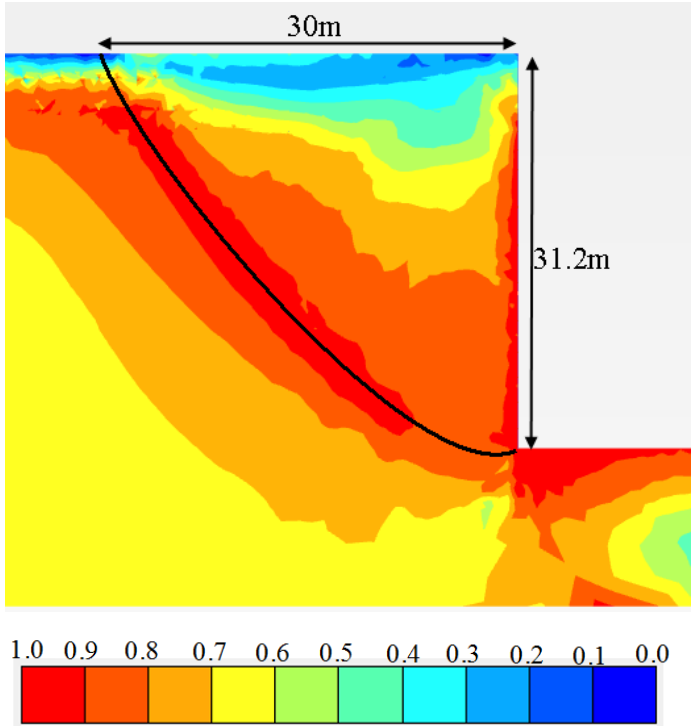

(a)

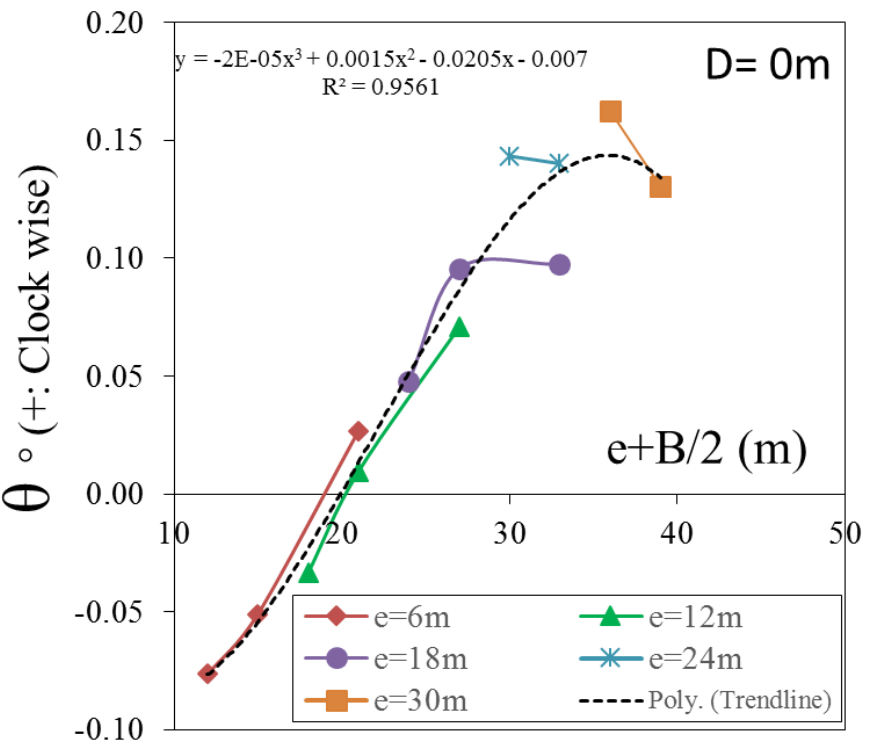

(c) 
Distance from excavation wall $(\mathrm{m})$

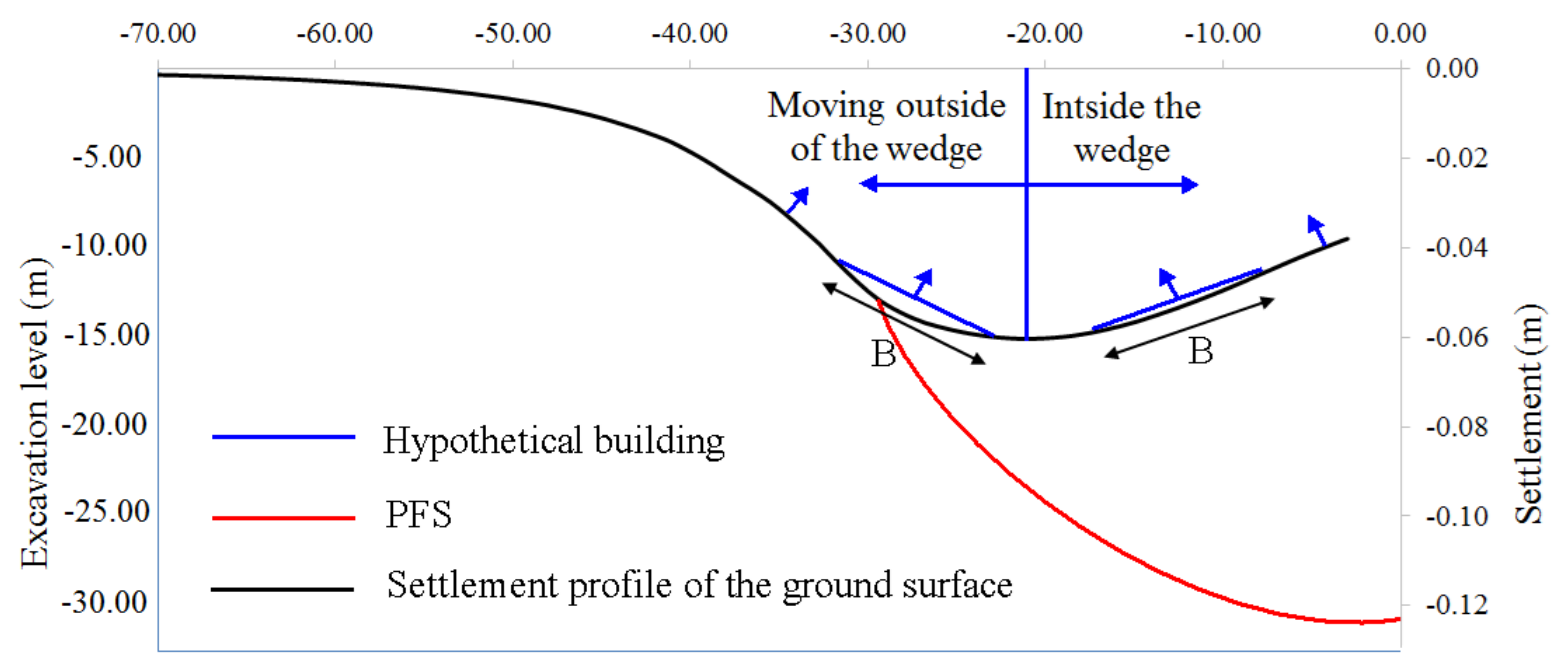

(b)

Figure 12. (a) Potential failure surface position in free field condition, (b) ground surface settlement profile together with slip surface position in free field condition and (c) the hypothetical buildings' rotation for different values of " $e+B / 2$ " in free field condition

Settlement profiles versus e for different $\mathrm{D}$ values of hypothetical buildings in free field conditions are depicted in Figure 13a. As D values increase, the corresponding soil volume and weight are removed and settlements decrease due to the reduction in the failure wedge surcharge. The decrease in settlements leads to the reduction of differential settlements and subsequently the rotations.

Figure $13 b$ depicts variations of $\theta$ versus $\mathrm{e}+\mathrm{B} / 2$ for different values of $\mathrm{D}$ in free field conditions. The trend lines, which have been fitted, represent the ground surface slope. As seen, higher values of $\mathrm{D}$ result in lower rotations, both clockwise and counter clockwise, of the building.
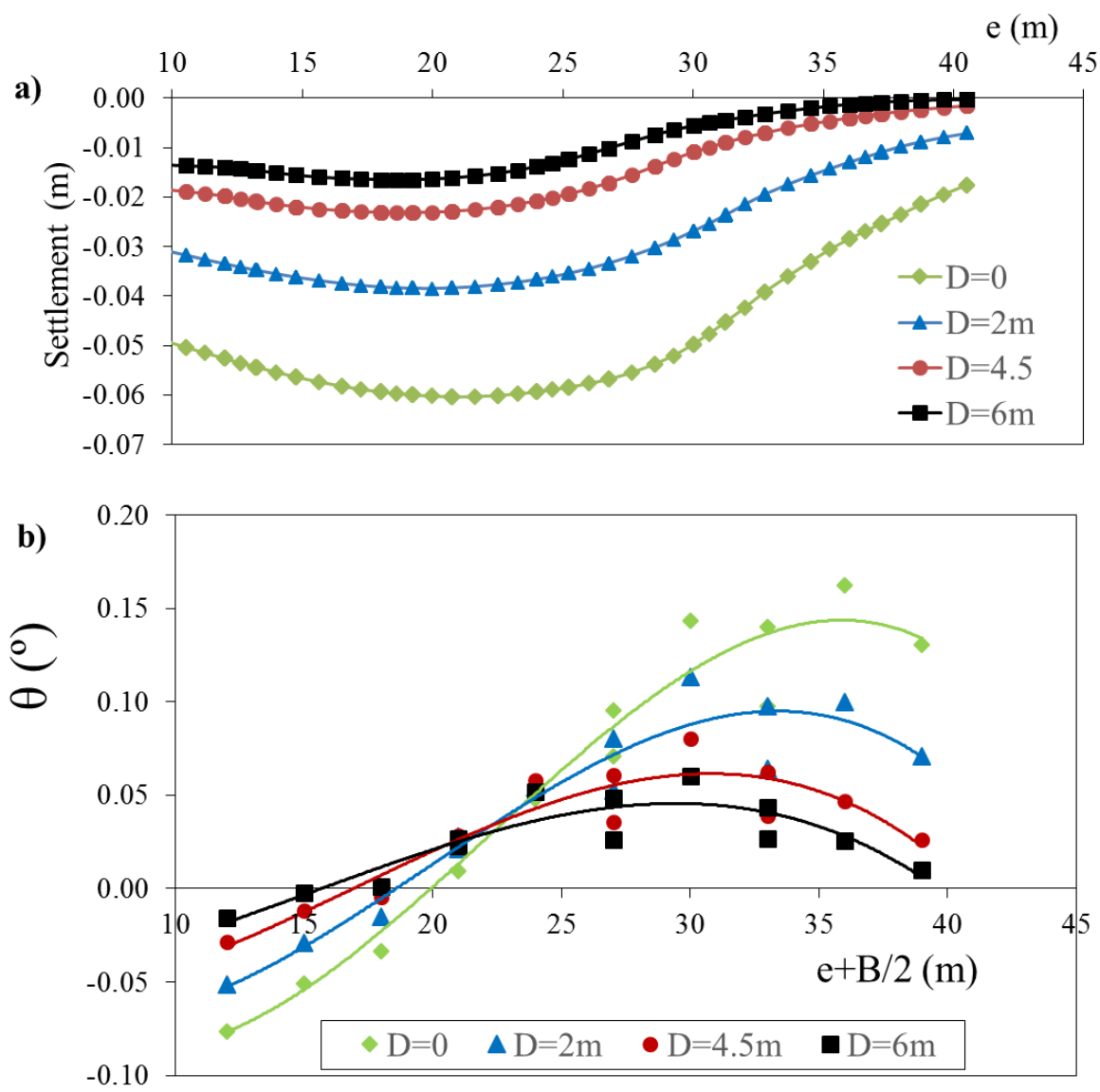

Figure 13. (a) Settlement profiles for different $D$ values of hypothetical buildings in free field condition, (b) The hypothetical buildings' rotation for different values of $D$ in free field condition 
In addition, by increasing embedment depth of the building (D), the part of the building which falls outside of the failure wedge becomes relatively larger; compare together the positions of the building in depth D1 and D2 in Figure 14. It is obvious that as the $\mathrm{D}$ becomes larger the chance for clockwise rotation of the building increases.

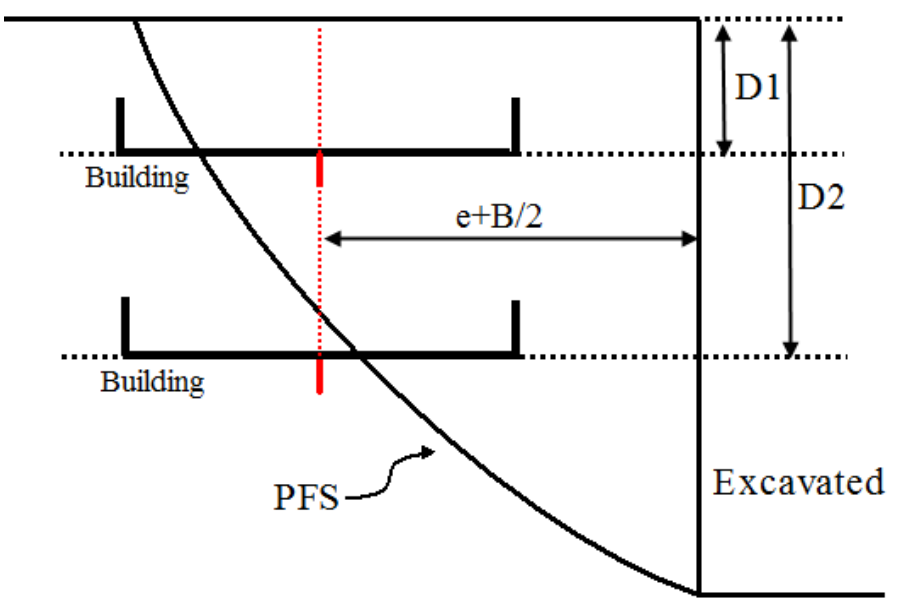

Figure 14. Effects of $D$ on a building position with respect to the PFS

Given the above conceptual framework for the building-excavation interaction, which developed based on the free field model, a series of parametric studies were carried out for different values of D, B, and e. Figures 15a, 15b, and 15c illustrate the building rotation $(\theta)$ versus $B$ and different e values for $\mathrm{D}=2 \mathrm{~m}, 4.5 \mathrm{~m}$, and $6 \mathrm{~m}$, respectively. According to these figures for given D and e, $\theta$ increases generally (i.e., switch to more a clockwise direction) as B becomes larger. This was explained in Sec 4.1 (Figure 14) that the building moves toward the PFS boundary as B becomes larger. There are a few exceptions (e.g., e=0 and 6 in Figure 15a and e=0 in Figure 15b) in which increasing of B from $12 \mathrm{~m}$ to $18 \mathrm{~m}$ has rotated the building in counter clockwise direction. This is because in these cases, the building is still inside the PFS with a safe margin; however, the weight of the building (due to enlarging B) has increased, and lead to rotation that is more negative. This exception is suppressed as D increases in Figures $15 \mathrm{c}$.
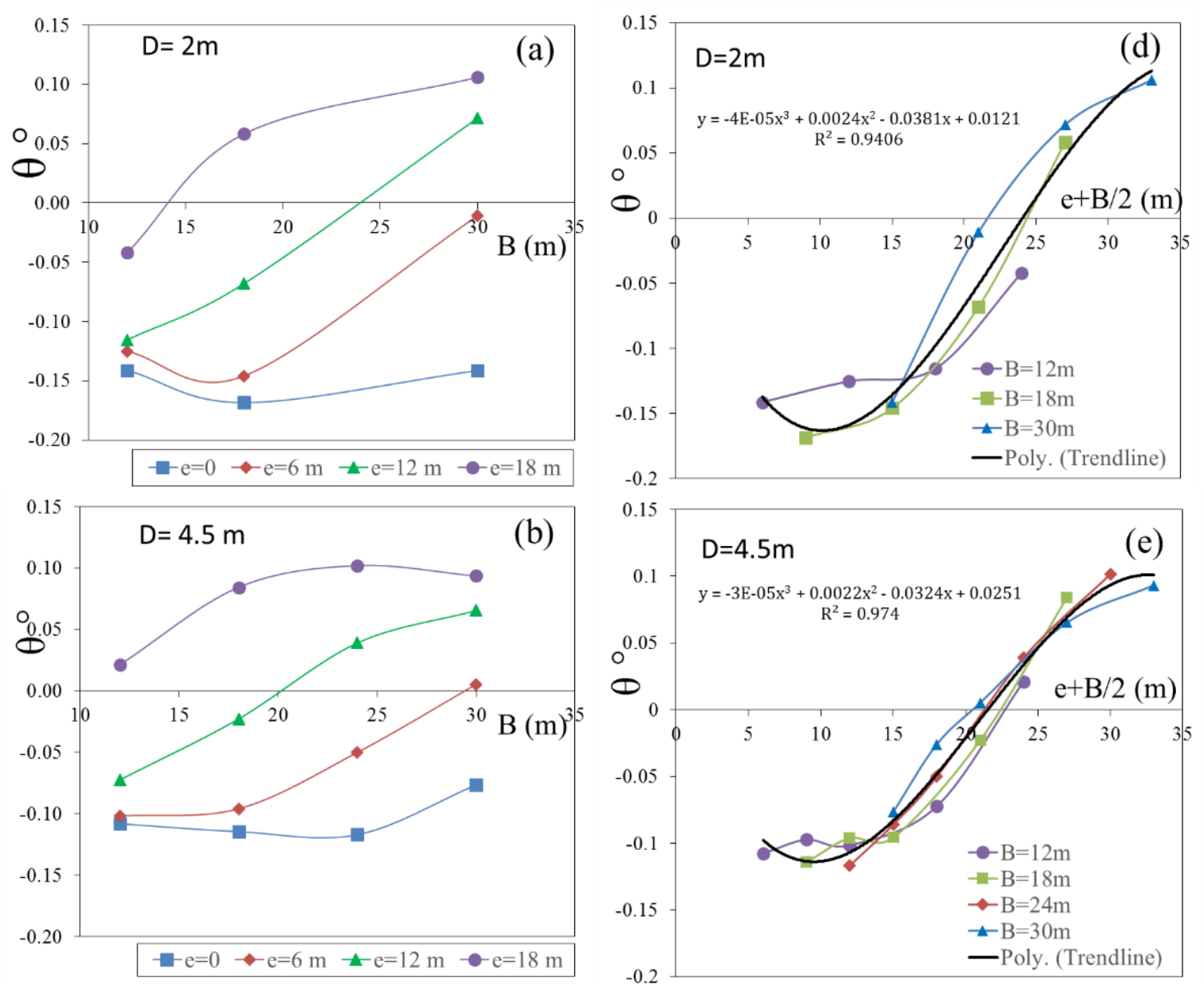

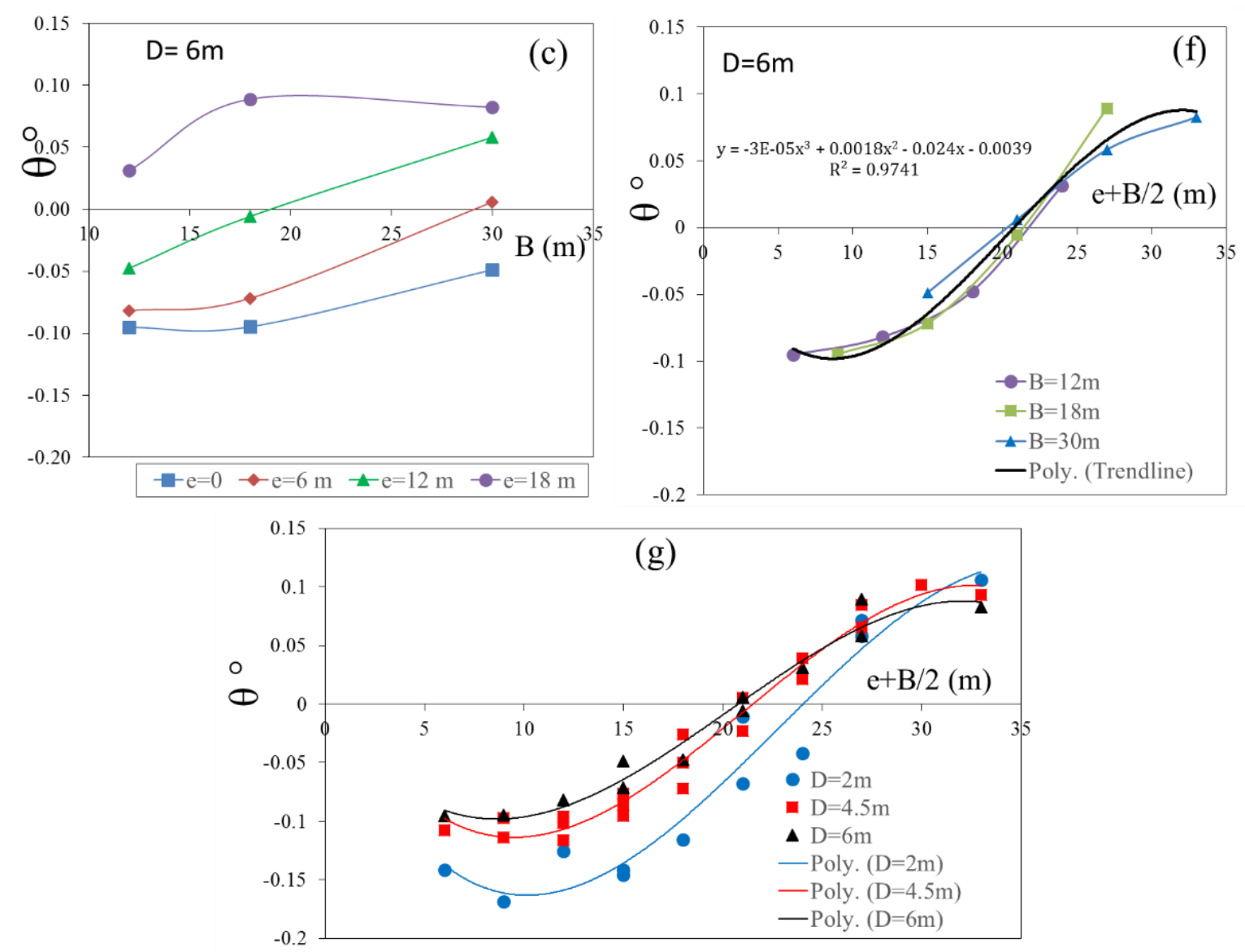

Figure 15. Building rotation ( $\theta$ ) for different values of $B, D$ and $e$ in the parametric study

Figure $15 \mathrm{~d}, 15 \mathrm{e}$, and $15 \mathrm{f}$ present the same results of the parametric study in terms of the building rotation $(\theta)$ versus $\mathrm{e}+\mathrm{B} / 2$ and different $\mathrm{B}$ values for $\mathrm{D}=2 \mathrm{~m}, 4.5 \mathrm{~m}$, and $6 \mathrm{~m}$, respectively. As seen, the results, including the trend lines, follow the same general trend, and they are favorably comparable with the conceptual framework introduced in Figure $12 \mathrm{c}$.

Moreover, the trend lines of $\theta$ variations from the above three figures are redrawn in Figure $15 \mathrm{~g}$, which compares favorably with the conceptual framework for the free field model shown in Figure 13b.

\subsection{Excavation Wall Horizontal Displacement $\left(\mathbf{U}_{c}\right)$}

We expect that $\mathrm{U}_{\mathrm{c}}$ be dependent upon $\mathrm{B}, \mathrm{D}$, e and more importantly building location with respect to the PFS. Plots of Figure 16 assess the level of dependency of $U_{c}$ to each of the above variables. In this regard, Figures 16a, 16b and $16 \mathrm{c}$ reveal two important findings, as follows. (1) Weight of the building (due to increasing of B while most part of the building still inside the PFW) is responsible for the cases in which an increase in B is followed by an increase in $U_{c}$. (2) Locating most part of the building (due to extension of the building width, B, beyond the PFS boundary) is responsible for the cases in which an increase in $\mathrm{B}$ has led to a decrease in $\mathrm{U}_{\mathrm{c}}$. In other words in the latter, that part of $\mathrm{B}$, and its corresponding weight and stiffness, beyond the PFW has controlled and restricted horizontal movements of the excavation.

Figures 16d, 16e, and $16 \mathrm{f}$ suggest that for a given B, horizontal displacement of the excavation crest, $\mathrm{U}_{\mathrm{c}}$, proportionally decreases with $\mathrm{D}$ for all of the e values. The observed $\mathrm{U}_{\mathrm{c}}$ reductions by increase in $\mathrm{D}$, is attributable to two main reasons; i) the soil weight removal corresponding to the lowered depths of the building foundation which cause surcharge reduction on the wedge, and ii) the fact that more parts of the building exit the PFW area due to smaller failure wedge. It is instructive that for $\mathrm{B}=12 \mathrm{~m}$, in which $\mathrm{B}+\mathrm{e}$ is less than the width of $\mathrm{PFW}$, the variation of $\mathrm{U}_{\mathrm{c}}$ is almost independent of e. 

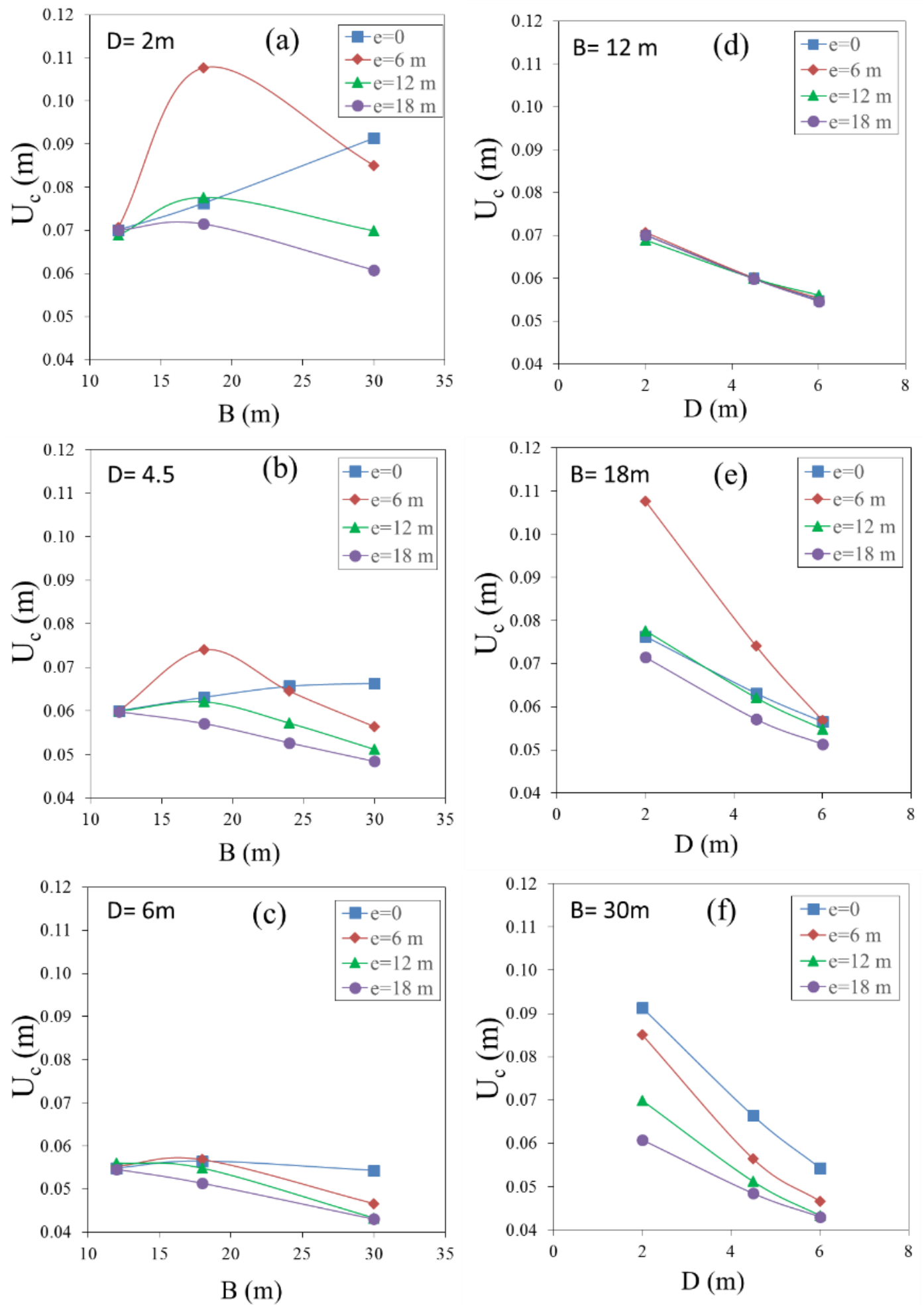

Figure 16. Horizontal displacement of the crest $\left(U_{c}\right)$ for different values of $B, D$ and $e$ of building

\subsection{Maximum Settlement of Building $\left(\mathrm{S}_{\mathrm{b}}\right)$}

Considering what we elaborated in Section 4.1 regarding the potential failure surface, PFS (Figures 10 and 11) and Section 4.2 (building rotation, $\theta$; Figure 12), one expect that like $U_{\mathfrak{c}}$, the maximum settlement of the building $\left(\mathrm{S}_{\mathrm{b}}\right)$ be dependent upon variables such as B, D, e, weight of the building, and its location with respect to the PFS. Another parameter that may affect $S_{b}$ is the proximity of the building and particularly the location of its maximum settlement to the supporting system of the excavation wall, as indicated in Figure 13a; the supporting system generally enhances the global stiffness of the soil that limit the soil settlements in this area. Having all of the foregoing explanations in mind, Figure 17 shows variations and dependency of $S_{b}$ with regard to the varying parameters of $D, B$, and $e$.

The values and trends of these variations can be explained and justified one by one, considering specific effects of each influencing parameter. For the purpose of brevity, this explanation is not presented here. 

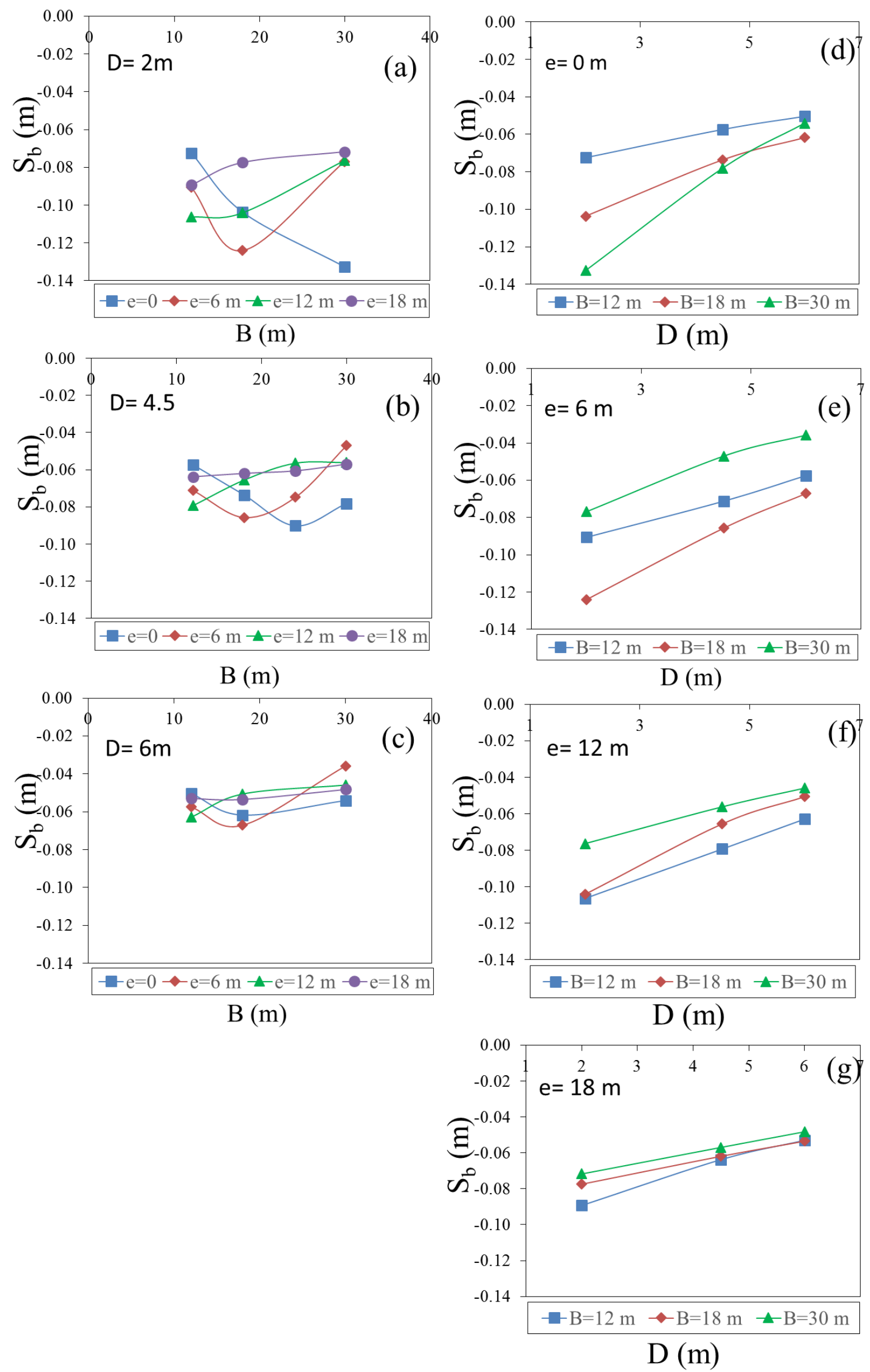

Figure 17. Maximum building settlement $\left(S_{b}\right)$ for different values of $B, D$ and $e$ 


\section{Conclusions}

This paper presented results of a parametric numerical study to investigate building related parameters (i.e., building width, B, embedment depth, D, and building distance from the excavation crest, e) affecting the interaction of an anchored piled deep excavation in a relatively dense granular cementitious soil with a nearby framed building. The numerical modeling approach in the parametric study was verified by a case study. Horizontal displacement of the excavation crest $\left(U_{c}\right)$, maximum settlement of the adjacent building $\left(S_{b}\right)$ and rotation of the building $(\theta)$ were investigated in the parametric study. The main results drawn from this study are summarized, as follows:

- Building characteristics have little impact on the position of the potential failure surface, PFS, in the soil developed by the excavation.

- The building position in relation to the potential slip surface is an important factor affecting rotations and displacements of the building due to excavation. This factor provides a useful framework for interpretation and prediction of the responses $\left(\theta\right.$ and $\left.\mathrm{S}_{\mathrm{b}}\right)$ of the nearby building, as well as the excavation wall, $\mathrm{U}_{\mathrm{c}}$.

- The rotation of the building is interpreted based on the free field model. As long as the building locates inside the potential failure wedge, the rotation is counter clockwise (for the geometry of this research). As the building moves away from the excavation, its rotation reduces gradually and when the building distances more from the excavation edge (i.e., some part of the building locates outside of the potential failure wedge, PFW), the building rotation shifts to the clockwise direction.

- Increasing the building embedment depth, D, reduces width of the failure wedge at the level of foundation base. In other words, increasing D has the same effects as of moving the building outward the failure wedge. This means that for a given $\mathrm{B}$, increasing D pushes the building toward outside of the PFW.

- The building's position relative to the potential failure surface together with the effective surcharge on the wedge (weight of that part of the building inside PFW) and the building stiffness are responsible for the rotation, $\theta$, and settlement of the building, $\mathrm{S}_{\mathrm{b}}$, as well as the horizontal displacement of the excavation crest, $\mathrm{U}_{\mathrm{c}}$.

\section{Acknowledgements}

Efforts of Dr. R. Shafipour and Dr. P. Tabatabaie Shourijeh are highly acknowledged for their thoroughly checking and reviewing the paper.

\section{Conflicts of Interest}

The authors declare no conflict of interest.

\section{References}

[1] Basmaji, B., O. Deck, and M.A. Heib. “Analytical Model to Predict Building Deflections Induced by Ground Movements." European Journal of Environmental and Civil Engineering 23, no. 3 (February 2017): $409-431$. doi:10.1080/19648189.2017.1282382.

[2] Bryson, L.S., and D.G. Zapata-Medina. "Method for Estimating System Stiffness for Excavation Support Walls." Journal of Geotechnical and Geoenvironmental Engineering 138, no. 9 (September 2012): 1104-1115. doi:10.1061/(asce)gt.19435606.0000683 .

[3] Castaldo, P., M. Calvello, and B. Palazzo. "Probabilistic Analysis of Excavation-Induced Damages to Existing Structures." Computers and Geotechnics 53 (September 2013): 17-30. doi:10.1016/j.compgeo.2013.04.008.

[4] Cording, E.J., J.L. Long, M. Son, D. Laefer, and B. Ghahreman. “Assessment of Excavation-Induced Building Damage.” Earth Retention Conference 3 (July 2010). doi:10.1061/41128(384)7.

[5] Laefer, D.F., S. Ceribasi, J.H. Long, and E.J. Cording. "Predicting RC Frame Response to Excavation-Induced Settlement." Journal of Geotechnical and Geoenvironmental Engineering 135, no. 11 (November 2009): 1605-1619. doi:10.1061/(asce)gt.1943-5606.0000128.

[6] Kim S, Finno RJ, (2019) Inverse Analysis of a Supported Excavation in Chicago. J. Geotech. Geoenviron. Eng., ASCE 145 (9). https://doi.org/10.1061/(ASCE)GT.1943-5606.0002120.

[7] Zhang, W., Z. Hou, A.T.C. Goh, and R. Zhang. "Estimation of Strut Forces for Braced Excavation in Granular Soils from Numerical Analysis and Case Histories." Computers and Geotechnics 106 (February 2019): 286-295. doi:10.1016/j.compgeo.2018.11.006.

[8] Khoshnevisan, S., L. Wang, and C.H. Juang. "Practical Robust Geotechnical Design of Supported Excavations-A Case History of Excavation in Taiwan." Geotechnical Frontiers 2017 (March 2017). doi:10.1061/9780784480458.018. 
[9] Son, M., and E.J. Cording. "Responses of Buildings with Different Structural Types to Excavation-Induced Ground Settlements." Journal of Geotechnical and Geoenvironmental Engineering 137, no. 4 (April 2011): 323-333. doi:10.1061/(asce)gt.19435606.0000448 .

[10] Goh, K.H., and R.J. Mair. "Response of Framed Buildings to Excavation-Induced Movements." Soils and Foundations 54, no. 3 (June 2014): 250-268. doi:10.1016/j.sandf.2014.04.002.

[11] Fargnoli, V., C.G. Gragnano, D. Boldini, and A. Amorosi. “3D Numerical Modelling of Soil-structure Interaction During EPB Tunnelling.” Géotechnique 65, no. 1 (January 2015): 23-37. doi:10.1680/geot.14.p.091.

[12] Naeij, M., A. Soroush, and Y. Javanmardi. "Numerical Investigation of the Effects of Embedment on the Reverse FaultFoundation Interaction.” Computers and Geotechnics 113 (September 2019): 103098. doi:10.1016/j.compgeo.2019.103098.

[13] Houhou, M.N., F. Emeriault, and A. Belounar. "Three-Dimensional Numerical Back-Analysis of a Monitored Deep Excavation Retained by Strutted Diaphragm Walls.” Tunnelling and Underground Space Technology 83 (January 2019): 153-164. doi:10.1016/j.tust.2018.09.013.

[14] Mirhabibi, A., and A. Soroush. "Effects of Building Three-Dimensional Modeling Type on Twin Tunneling-Induced Ground Settlement.” Tunnelling and Underground Space Technology 38 (September 2013): 224-234. doi:10.1016/j.tust.2013.07.003.

[15] Zhao C, Schmüdderich C, Barciaga T, Röchter L, (2019) Response of building to shallow tunnel excavation in different types of soil. Computers and Geotechnics 115. https://doi.org/10.1016/j.compgeo.2019.103165.

[16] Son, M., and E.J. Cording. "Evaluation of Building Stiffness for Building Response Analysis to Excavation-Induced Ground Movements." Journal of Geotechnical and Geoenvironmental Engineering 133, no. 8 (August 2007): 995-1002. doi:10.1061/(asce)1090-0241(2007)133:8(995).

[17] Cai, Y., T. Verdel, and O. Deck. "Using Plane Frame Structural Models to Assess Building Damage at a Large Scale in a Mining Subsidence Area." European Journal of Environmental and Civil Engineering (September 2017): 1-24. doi:10.1080/19648189.2017.1379911.

[18] Goh, K.H., and R.J. Mair. "Building damage assessment for deep excavations in Singapore and the influence of building stiffness." Geotechnical Engineering 42 (September 2011): 1-12.

[19] Elshafie, M.Z.E.B., C.K.C. Choy, and R.J. Mair. “Centrifuge Modeling of Deep Excavations and Their Interaction With Adjacent Buildings.” Geotechnical Testing Journal 36, no. 5 (July 2013): 20120209. doi:10.1520/gtj20120209.

[20] Ou, C.Y., P.G. Hsieh, and D.C. Chiou. "Characteristics of Ground Surface Settlement During Excavation." Canadian Geotechnical Journal 30, no. 5 (October 1993): 758-767. doi:10.1139/t93-068.

[21] Chhengil C, Likitlersuang S (2018) Underground excavation behaviour in Bangkok using 3D finite element method. Computers and Geotechnics 95: 68-81. https://doi.org/10.1016/j.compgeo.2017.09.016.

[22] Russo G, Nicotera MV, Autuori S, (2019) 3D Performance of a Deep Excavation in Sand. J. Geotech. Geoenviron. Eng., ASCE 145 (4). https://doi.org/10.1061/(ASCE)GT.1943-5606.0002037.

[23] Yang X, Jia M, Ye J, (2020) Method for estimating wall deflection of narrow excavations in clay. Computers and Geotechnics 117. https://doi.org/10.1016/j.compgeo.2019.103224.

[24] Fuentes R, Devriendt M, (2010) Ground Movements around Corners of Excavations: Empirical Calculation Method. J. Geotech. Geoenviron. Eng., ASCE 136 (10). https://doi.org/10.1061/(ASCE)GT.1943-5606.0000347.

[25] Wang ZZ, Goh SH, Koh CG, Smith LFC, (2019) An efficient inverse analysis procedure for braced excavations considering 3D effects. Computers and Geotechnics 107: 150-162. https://doi.org/10.1016/j.compgeo.2018.12.004. [26] Chheng, C., and S. Likitlersuang. "Underground Excavation Behaviour in Bangkok Using Three-Dimensional Finite Element Method." Computers and Geotechnics 95 (March 2018): 68-81. doi:10.1016/j.compgeo.2017.09.016.

[27] PLAXIS 3D 2017 reference manual, Delft University of technology and PLAXIS bv., The Netherlands.

[28] Chen, Ha., J. Li, and L. Li. "Performance of a Zoned Excavation by Bottom-Up Technique in Shanghai Soft Soils." Journal of Geotechnical and Geoenvironmental Engineering 144, no. 11 (November 2018): 05018003. doi:10.1061/(asce)gt.19435606.0001964 . 